\title{
A cell cycle-dependent protein serves as a template-specific translation initiation factor
}

\author{
Evgeny V. Pilipenko, ${ }^{1,2,4}$ Tatyana V. Pestova, ${ }^{2,3,5}$ Victoria G. Kolupaeva, ${ }^{2}$ Elena V. Khitrina, ${ }^{1}$ \\ Angela N. Poperechnaya, ${ }^{3}$ Vadim I. Agol, ${ }^{1,3}$ and Christopher U.T. Hellen ${ }^{2}$ \\ ${ }^{1}$ Institute of Poliomyelitis and Viral Encephalitides, Russian Academy of Medical Sciences, Moscow 142782, Russia; \\ ${ }^{2}$ Department of Microbiology and Immunology, State University of New York Health Science Center at Brooklyn, Brooklyn, \\ New York 11203 USA; $^{3}$ A. N. Belozersky Institute of Physico-Chemical Biology, Moscow State University, Moscow 119899, \\ Russia
}

Cap-independent translation initiation on picornavirus mRNAs is mediated by an internal ribosomal entry site (IRES) in the $5^{\prime}$ untranslated region (5' UTR) and requires both eukaryotic initiation factors (eIFs) and IRES-specific cellular trans-acting factors (ITAFs). We show here that the requirements for trans-acting factors differ between related picornavirus IRESs and can account for cell type-specific differences in IRES function. The neurovirulence of Theiler's murine encephalomyelitis virus (TMEV; GDVII strain) was completely attenuated by substituting its IRES by that of foot-and-mouth disease virus (FMDV). Reconstitution of initiation using fully fractionated translation components indicated that $48 \mathrm{~S}$ complex formation on both IRESs requires eIF2, eIF3, eIF4A, eIF4B, eIF4F, and the pyrimidine tract-binding protein (PTB) but that the FMDV IRES additionally requires $\operatorname{ITAF}_{45}$, also known as murine proliferation-associated protein (Mpp1), a proliferation-dependent protein that is not expressed in murine brain cells. ITAF $_{45}$ did not influence assembly of 485 complexes on the TMEV IRES. Specific binding sites for ITAF $_{45}$, PTB, and a complex of the eIF4G and eIF4A subunits of eIF4F were mapped onto the FMDV IRES, and the cooperative function of PTB and ITAF 45 in promoting stable binding of eIF4G/4A to the IRES was characterized by chemical and enzymatic footprinting. Our data indicate that PTB and ITAF $_{45}$ act as RNA chaperones that control the functional state of a particular IRES and that their cell-specific distribution may constitute a basis for cell-specific translational control of certain mRNAs.

[Key Words: IRES; ITAF 45 ; picornavirus; RNA-binding proteins; translation initiation]

Received April 24, 2000; revised version accepted June 23, 2000.

The control of mRNA translation is an important component of the regulation of gene expression, and various cellular processes are regulated by enhancement or repression of translation initiation. Message-specific translational control relies on structural elements in either $5^{\prime}$ or $3^{\prime}$ nontranslated regions of mRNAs that may bind regulatory proteins, determine the affinity of binding of canonical translation initiation factors, or enable mRNAs to utilize variants of the canonical initiation mechanism (Standart and Jackson 1994).

Most examples of mRNA-specific translational control involve repression by RNA-binding proteins. Repression of initiation is exemplified by ferritin mRNA, one of a group of mRNAs that contain a cap-proximal 5' UTR iron-responsive element (IRE; Hentze and Kühn 1996).

\footnotetext{
${ }^{4}$ Present address: Department of Neurology, University of Chicago Medical Center, Chicago, IL 60637 USA.

${ }^{5}$ Corresponding author.

E-MAIL tpestova@netmail.hscbklyn.edu; FAX (718) 270-2656.
}

Binding of the iron regulatory protein to the IRE sterically prevents recruitment by eIF4F of the $43 \mathrm{~S}$ ribosomal complex to the cap-proximal region of the 5' UTR before scanning to the initiation codon and thus represses translation (Muckenthaler et al. 1998). RNA protein interactions can also direct patterns of expression that are spatially restricted within cells or organisms, for example, during development or differentiation, and commonly involve repression of translation of specific mRNAs by regulatory 3' UTR-binding proteins (Gray and Wickens 1998). Translational enhancement of specific mRNAs is less common. All mRNAs that are translated following conventional cap-mediated initiation require the full set of canonical eIFs, and variations in initiation factor levels have not been associated with translational enhancement of specific mRNAs that use this mechanism. Cell type-specific translational regulation is more likely to affect those mRNAs that require noncanonical protein factors for initiation in addition to the canonical set of eIFs. 
Picornavirus 5' NTRs contain a 400-nt-long internal ribosomal entry site (IRES) that mediates cap-independent translation initiation (Jackson and Kaminski 1995). These IRESs are divided into major groups on the basis of structural properties. One group includes poliovirus and rhinovirus and the other contains encephalomyocarditis virus (EMCV), foot-and-mouth disease virus (FMDV), and Theiler's murine encephalomyelitis virus (TMEV). There is significant genetic evidence that IRESs contain determinants of cell specificity. A mutant poliovirus in which the IRES had been substituted by the rhinovirus IRES replicated as well as wild-type poliovirus in HeLa cells, but replication of the mutant (but not wild-type) viruses was completely restricted in neuronal cells (Gromeier et al. 1996). Single substitutions in the IRESs of poliovirus vaccine strains are important determinants of their attenuated neurovirulence and impaired function in translation initiation, particularly in neural cells (Svitkin et al. 1985, 1988). Mutations in the IRES also attenuate TMEV neurovirulence in mice while having only minor effects on viral growth in cell culture (Pritchard et al. 1992; Pilipenko et al. 1995, 1999). Although such noncoding determinants of IRES function have been characterized in detail, the molecular basis for their cell-specific influence is not known.

IRES-mediated initiation may require both canonical initiation factors and message-specific cellular IRES trans-acting factors (ITAFs) that are not involved in capmediated initiation. EMCV, TMEV, and FMDV IRESs are all active in rabbit reticulocyte lysate (RRL), where translation mediated by poliovirus and rhinovirus IRESs is inefficient unless the lysate is supplemented by HeLa cell extracts (Brown and Ehrenfeld 1979; Dorner et al. 1984; Borman et al. 1993). Biochemical analyses led to the identification of the ITAFs present in these extracts as the pyrimidine tract-binding protein $(\mathrm{PTB}$; Borman et al. 1993; Hellen et al. 1993), the La autoantigen (Meerovitch et al. 1993; Svitkin et al. 1994), the poly(rC)-binding protein 2 (PCBP2; Blyn et al. 1996, 1997), and unr and a unr-interacting protein (Hunt et al. 1999). All of these proteins except for the unr-interacting protein are RNAbinding proteins that bind specifically to structural elements in different IRESs and are thought to maintain these RNAs in an active conformation (Kaminski and Jackson 1998; Kolupaeva et al. 1998; Gamarnik and Andino 2000). A reasonable hypothesis is therefore that tissue-specific differences in the expression of an essential ITAF could determine those cells in which the IRES is active.

We report here the identification of a novel cellular mRNA-specific ITAF. We found that the activities of TMEV and FMDV IRESs were similar in RRL and in transfected BHK-21 cells but that replacement of the IRES of the neurotropic TMEV by the IRES of the epitheliotropic FMDV yielded viable but completely attenuated viruses that fail to replicate in mouse neurons. To identify the factor that is required for FMDV IRES function, we compared the factor requirements for initiation on TMEV and FMDV IRESs by biochemical reconstitution to the stage of $48 \mathrm{~S}$ complex formation using fully fractionated components. Using this approach, we have previously found that initiation on the EMCV IRES up to the stage of $48 \mathrm{~S}$ complex formation requires the canonical factors eIF2, eIF3, eIF4A, eIF4B, and eIF4F, and is enhanced less than twofold by PTB (Pestova et al. 1996a, 1996b). We also report that 48S complex formation on FMDV and TMEV IRESs requires the same set of canonical factors and that initiation on all three IRESs involves specific binding of a complex made up of the eIF4A and eIF4G components of eIF4F to the IRES. However, initiation on the TMEV IRES depended strongly on PTB, where initiation on the FMDV IRES required both PTB and a second protein, $\mathrm{ITAF}_{45}$, that is not required for TMEV initiation. ITAF ${ }_{45}$ bound specifically to a central domain of the FMDV IRES and acted synergistically with PTB to enhance binding of eIF4F to an adjacent domain. $\mathrm{ITAF}_{45}$ is a proliferation-dependent protein that is not detectable in murine brain cells and may thus function as a tissue-specific factor that controls translation of particular mRNAs.

\section{Results}

In vitro properties of TMEV GDVII/FMDV chimeras

TMEV GDVII causes rapid fatal encephalitis in mice following intracerebral inoculation due to lytic infection of neurons (Theiler 1937). FMDV replicates in epithelial cells, causing an acute systemic infection, but does not replicate in the central nervous system /CNS; Bachrach 1968). We used FMDV and TMEV IRESs to investigate the molecular basis for cell-specific differences in IRES function. Chimeric GD68 and GD80 variants of TMEV GDVII were made by substituting its IRES by the FMDV IRES. IRES-mediated translation was assessed using constructs in which the luciferase coding region had been fused to TMEV nt 1-1124 in frame and downstream of the initiation codon $\mathrm{AUG}_{1068-70}$ (Fig. 1A). In the pLGF68 and pLGF-80 chimeras, TMEV sequences from nt 628 (upstream of domain $\mathrm{H}$ ) to either nt 1047 (the pyrimidine tract) or nt 1124 (past $\mathrm{AUG}_{1068-70}$ ) were replaced by equivalent FMDV sequences (nt 280-693 or nt 280-740, respectively; Forss et al. 1984). These substitutions had little effect on the efficiency of translation in RRL, and both caused a small reduction in IRES-mediated translation in BHK-21 cells (Fig. 1B). TMEV containing these substitutions was viable and genetically stable in BHK21 cells, yielding plaques that were slightly reduced in diameter relative to wt TMEV GDVII (Fig. 1C).

\section{Attenuation of neurovirulence of TMEV GDVII/FMDV chimeric viruses}

Several picornavirus IRESs have restricted activity in some cells and therefore contain determinants of the pattern and severity of host viral infection. We assayed the neurovirulence of the chimeric GD68 and GD80 viruses in mice. No clinical signs were observed $6 \mathrm{wk}$ after intracerebral inoculation with up to $10^{8} \mathrm{TCD}_{50}$ of GD68 

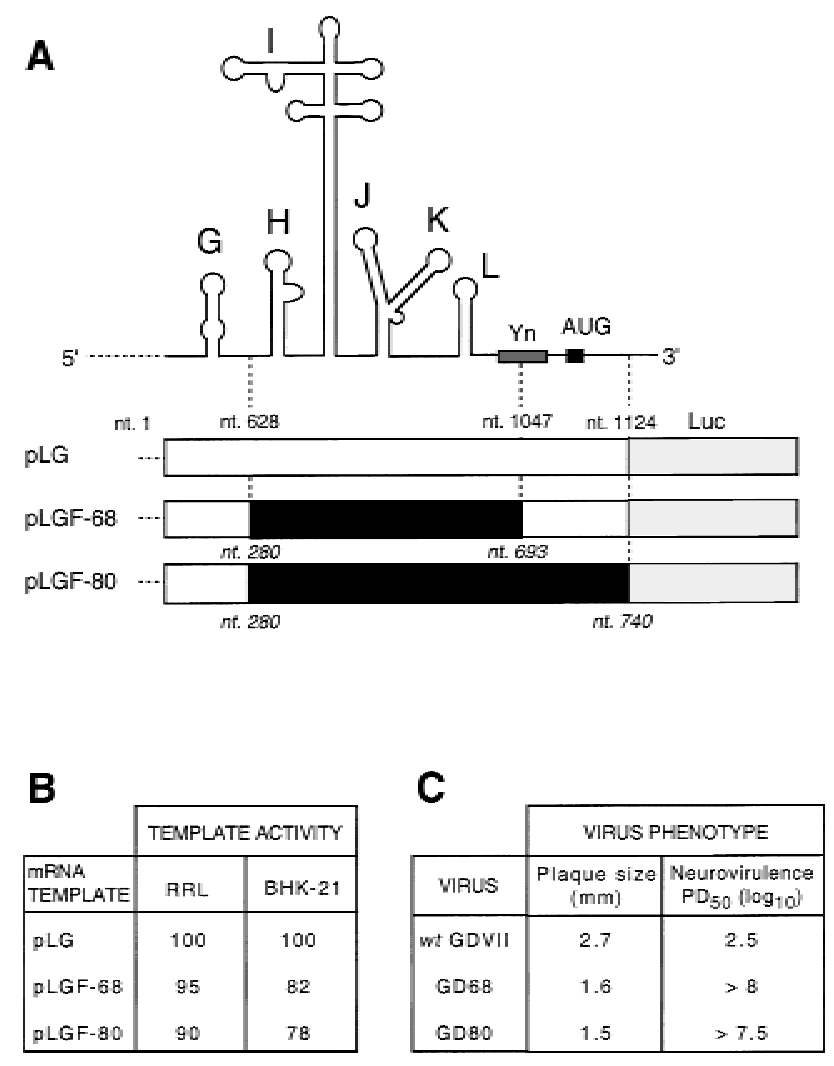

Figure 1. Structures of chimeric Theiler's murine encephalomyelitis virus (TMEV)/foot-and-mouth disease virus (FMDV) RNAs, template activities, and viral phenotypes. (A) Schematic representations of the TMEV IRES showing the positions of the oligopyrimidine tract $(\mathrm{Yn})$ and the initiation codon $\mathrm{AUG}_{1068-70}$ and of constructs derived from the recombinant cDNA for TMEV GDVII (white) and FMDV $0_{1} \mathrm{~K}$ (black) fused to a luciferase reporter gene (grey). The sizes of cDNA fragments used in these constructs are as indicated; TMEV nucleotide positions (Law and Brown 1990) are shown above pLG, and FMDV nucleotide positions are shown below pLGF-68 and pLGF-80. (B) Template activities of pLG, pLGF-68, and pLGF- 80 mRNA transcripts translated in RRL and in BHK-21 cells. $(C)$ In vitro growth characteristics and neurovirulence of $w t$ and chimeric TMEV GDVII viruses. Standard plaque assays were done using virus stocks produced by three accumulating passages posttransfection in BHK-21 cells, and plaques were measured 3 days postinfection. Neurovirulence was assayed by intracerebral inoculation of BALB/c mice with tenfold dilutions of virus. The paralytogenic activity of viruses was expressed as the $\mathrm{TCD}_{50}$ dose causing paralysis in $50 \%$ of animals $\left(\mathrm{PD}_{50}\right)$.

and up to $10^{7.5} \mathrm{TCD}_{50}$ of GD80 (Fig. 1C). For comparison, the $\mathrm{PD}_{50}$ of wt TMEV GDVII was $10^{2.5} \mathrm{TCD}_{50}$. Thus, GD68 and GD80 were completely attenuated as a consequence of replacing the TMEV IRES by that of FMDV. The sequences of these IRESs are $\sim 40 \%$ homologous (Kühn et al. 1990). Virus-specific PCR fragments were easily detected 1 day postinfection (p.i.) in all CNS samples from three mice inoculated with GD68 and from four mice inoculated with GD80. This result confirms that all mice were properly inoculated. Significantly, no virus-specific fragments were PCR-amplified from CNS samples prepared from the same number of mice 7 and 14 day p.i. Previously, we readily detected moderately attenuated TMEV mutant genomes up to 33 day p.i. (Pilipenko et al. 1995). TMEV GDVII replicates almost exclusively in neurons (Aubert and Brahic 1995). The results reported here imply that GD68 and GD80 did not replicate in the CNS and, more specifically, may be unable to interact functionally with the translational apparatus in neurons. These results indicated that cellspecific differences in the factors required for translation initiation could be analyzed using FMDV and TMEV IRESs.

\section{Factor requirements for initiation on the TMEV GDVII IRES}

IRES-mediated initiation involves recruitment of the 40S ribosomal subunit, Met-tRNA ${ }^{\mathrm{Met}}{ }_{\mathrm{i}}$, and eIFs to an internal site on an mRNA, leading to $48 \mathrm{~S}$ complex formation at the initiation codon. We identified the factors required for $48 \mathrm{~S}$ complex formation on the TMEV GDVII IRES by reconstituting this process in vitro, using purified translation components. The position of $48 \mathrm{~S}$ complexes on this mRNA was determined by toeprinting, which involves cDNA synthesis by reverse transcriptase on a template RNA to which a ribosome or protein is bound. cDNA synthesis is arrested by the bound complex, yielding toeprints at its leading edge. Eukaryotic $48 \mathrm{~S}$ complexes inhibit primer extension at positions that can vary from 14-21 nt $3^{\prime}$ to the A of the initiation codon depending on the mRNA on which the $48 \mathrm{~S}$ complexes have assembled (Pestova et al. 1996a, 1998a,b). The positions of toeprints described here are shown on a structural model of an appropriate segment of the TMEV IRES (Fig. 2A).

48S complexes accumulate when GMPPNP (a nonhydrolyzable GTP analog) is included with mRNA in RRL. Primer extension done on $48 \mathrm{~S}$ complexes assembled on wt TMEV GDVII mRNA in RRL in the presence of $1 \mathrm{~mm}$ GMPPNP yielded prominent toeprints 17 and $18 \mathrm{nt}$ and weaker toeprints 19 and $20 \mathrm{nt} 3^{\prime}$ to the $\mathrm{A}$ of $\mathrm{AUG}_{1068-70}$ (Fig. 3, lane 3).

We next assayed formation of $48 \mathrm{~S}$ complexes in vitro on this mRNA, using purified translation components. Incubation of TMEV GDVII mRNA with eIF2, eIF3, eIF4A, eIF4B, and eIF4F, PTB, 40S subunits, and MettRNA ${ }^{\mathrm{Met}}{ }_{\mathrm{i}}$ resulted in formation of $48 \mathrm{~S}$ complexes that yielded toeprints similar to those detected in RRL (Fig. $4 \mathrm{~A}$, lanes 5,9 . Each translation component was then individually omitted. PTB enhanced $48 \mathrm{~S}$ complex formation fivefold (average of six assays) (Fig. 4A, lanes 8,9). $48 \mathrm{~S}$ complex formation was absolutely dependent on $40 \mathrm{~S}$ subunits, Met-tRNA ${ }_{i}^{\text {Met }}$, eIF2, eIF3, and eIF4F (Fig. 4A, lanes 3,4; data not shown). eIF4A was present as a subunit of eIF4F, and these experiments therefore did not enable us to determine the requirement for eIF4A. Neither eIF1 nor eIF1A were required for $48 \mathrm{~S}$ complex formation (data not shown). This observation is consistent with reports that initiation on the TMEV IRES does not 
A

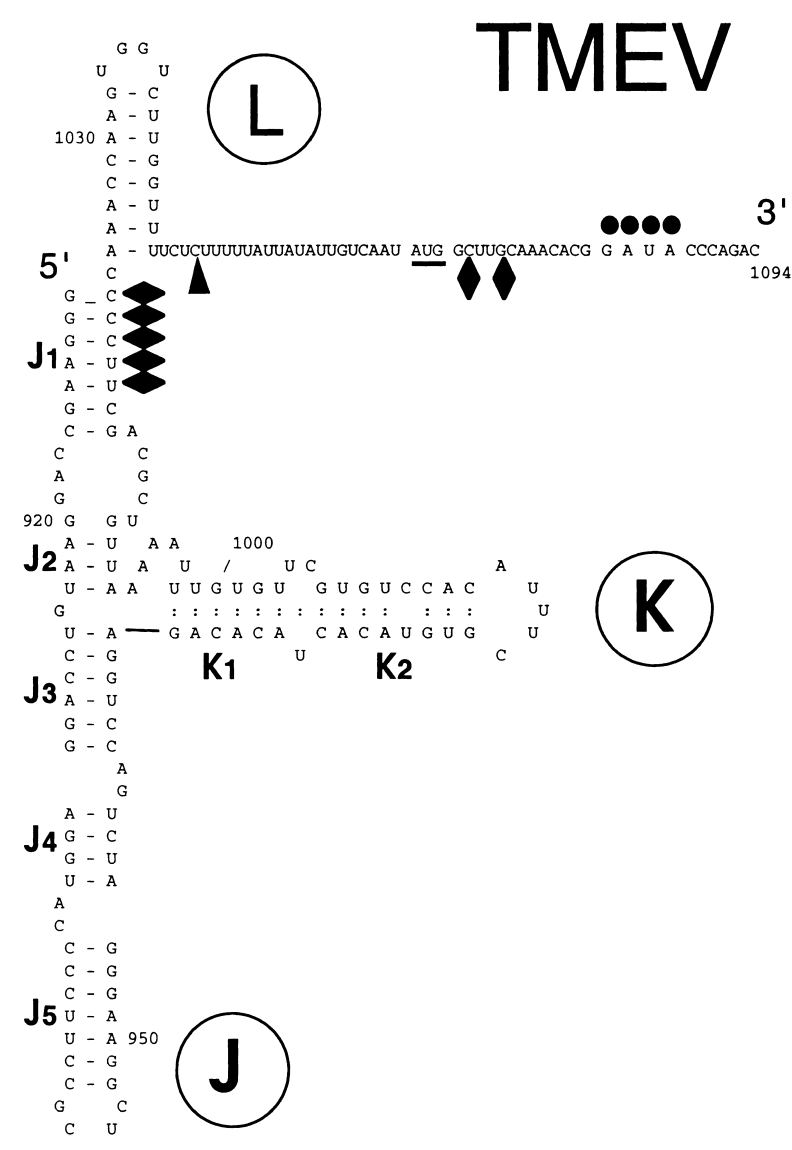

B

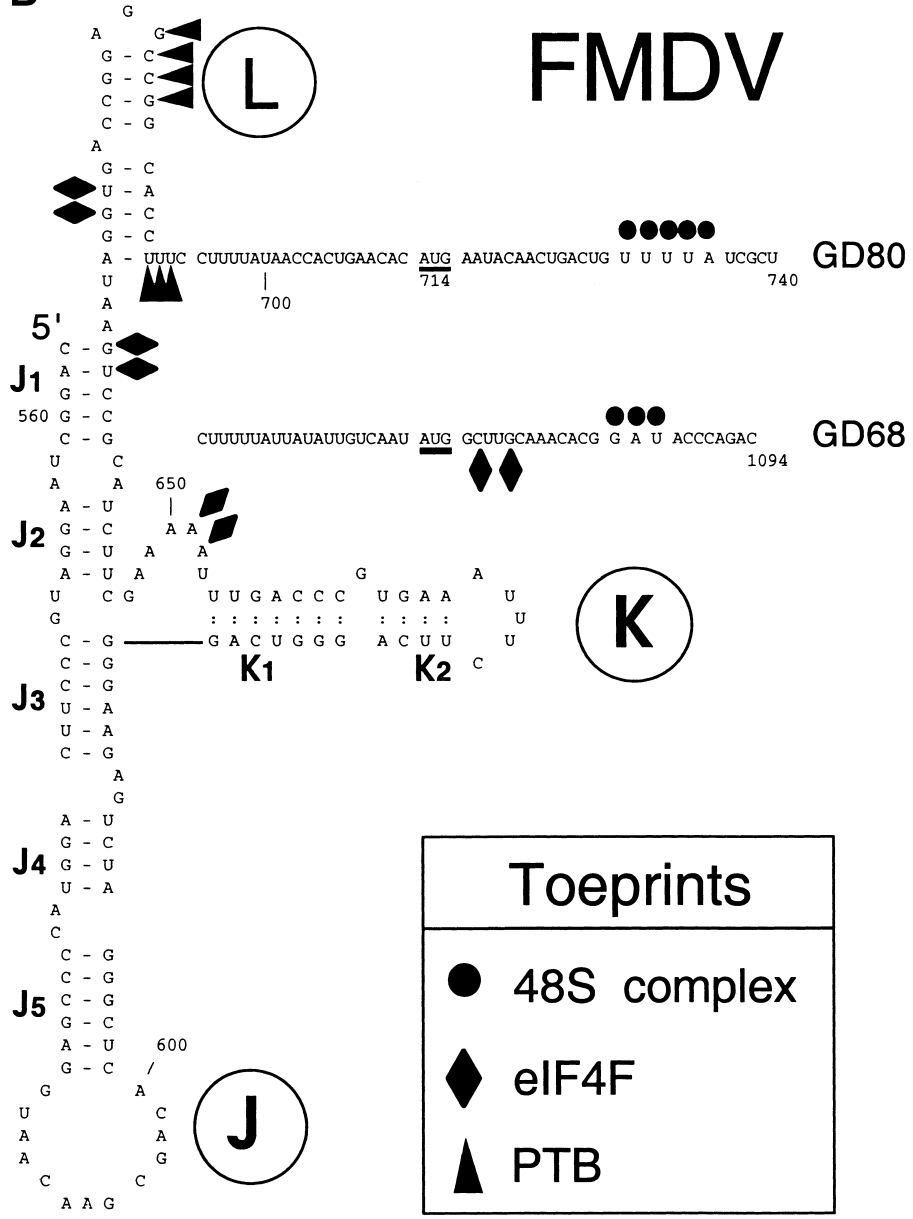

Figure 2. Secondary structures of segments of $(A)$ Theiler's murine encephalomyelitis virus (TMEV) GDVII and $(B)$ foot-and-mouth disease virus (FMDV) $0_{1} \mathrm{~K}$ internal ribosomal entry sites (IRESs; Pilipenko et al. 1989). The FMDV IRES was linked differently to downstream TMEV sequences in GD68 and GD80 as shown. FMDV and TMEV initiation codons are underlined. Prominent sites of $\mathrm{RT}$ arrest caused by eIF4F, PTB, and $48 \mathrm{~S}$ complexes are indicated by symbols as described in the key at bottom right.

involve scanning (Pilipenko et al. 1994) for which these two factors are absolutely required (Pestova et al. 1998a). Taken together, these results indicate that eIF2, eIF3, eIF4F, and possibly eIF4A and eIF4B constitute a minimum set of factors that are sufficient for $48 \mathrm{~S}$ complex formation on the TMEV IRES and that this process is strongly enhanced by PTB. We have previously found that eIF2, eIF3, eIF4A, eIF4B, and eIF4F constitute the minimum set of factors required for $48 \mathrm{~S}$ complex formation on the EMCV IRES and that this process is enhanced less than twofold by PTB (Pestova et al. 1996a).

Assembly reactions done using the TMEV IRES and all translation components also yielded prominent new toeprints at $\mathrm{UUCCC}_{1019-23}$ and weaker $\mathrm{C}_{1072}$ and $\mathrm{G}_{1075}$ toeprints (Fig. 4A, lanes 4,5,7-11). Their relative prominence increased on omission of $40 \mathrm{~S}$ subunits (Fig. 4A, lanes 4,5), suggesting that they result from binding of factors to the IRES. Stable complexes were formed by the binding of eIF4F to the IRES and yielded the same pattern of toeprints at UUCCC $_{1019-23}$ at the base of the J-K domain (Fig. 4B, lane 2). Mutations in the J-K domain that impair binding of eIF4F also strongly impair the ability of the IRES to support internal initiation and abrogate virus viability (T.V. Pestova and E.V. Pilipenko, unpubl.). The toeprints at $\mathrm{C}_{1072}$ and $\mathrm{G}_{1075}$ were seen only in the presence of eIF4F (Fig. 4A, cf. lanes 2 and 4), and they appear to be caused by the binding of a complex of its eIF4A and eIF4G subunits to the IRES because they were not observed in the presence of either eIF4G or eIF4A alone (E.V. Pilipenko and T.V. Pestova, unpubl.). These toeprints were strongly enhanced in reactions that contained PTB (Fig. 4A, cf. lanes 7,9,11 with lanes 8 and 10). This observation suggests that PTB binding facilitates formation of a specific ribonucleoprotein (RNP) complex on the GDVII IRES. Taken together, these results and previous reports (Pestova 1996a,b; Kolupaeva et al. 1998) suggest that the initiation processes on the related EMCV and TMEV IRESs differ in their requirement for PTB but that they otherwise occur by similar mechanisms that involve direct binding of eIF4F to the IRES upstream of the initiation codon and recruitment of a 43S complex. 


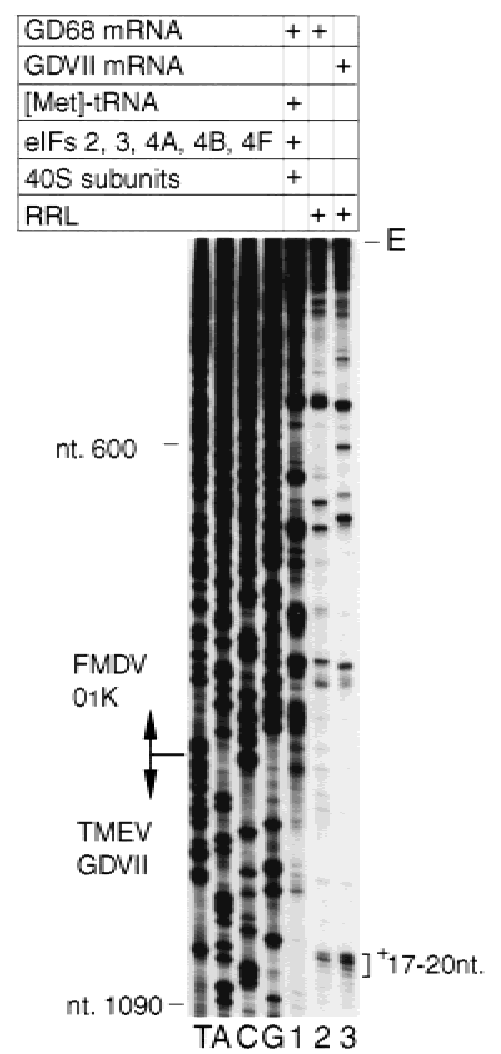

Figure 3. Toeprint analysis of $48 \mathrm{~S}$ complexes assembled on Theiler's murine encephalomyelitis virus (TMEV) GDVII and foot-and-mouth disease virus (FMDV) $0_{1} \mathrm{~K}$ internal ribosomal entry sites in RRL. TMEV GDVII mRNA (lane 3) and chimeric GD68 mRNA containing the FMDV IRES (lanes 1,2) were incubated in RRL (lanes 2,3) or with translation components as indicated (lane 1) under standard conditions for 48S complex formation. A primer was annealed to TMEV nt 1195-1214 in the coding region of these mRNAs and extended with AMV-RT. The full-length cDNA extension product is marked E. cDNA products labeled $+17-20 \mathrm{nt}$ terminated at these positions $3^{\prime}$ to the A of TMEV initiation codon $\mathrm{AUG}_{1068-70}$. Reference lanes $T$, $A, C$, and $G$ depict the negative-strand sequence derived using the same primer and GD68 plasmid DNA. The junction between TMEV GDVII and FMDV $0_{1} \mathrm{~K}$ nucleotides is indicated.

\section{TMEV and FMDV IRESs have different factor requirements for translation initiation}

Primer extension done on $48 \mathrm{~S}$ complexes assembled in RRL on the FMDV IRES yielded toeprints similar to those detected on the wt TMEV IRES (Fig. 3, lanes 2,3). The FMDV IRES therefore also promotes $48 \mathrm{~S}$ complex assembly precisely at the initiation codon, and RRL contains all necessary activities for this process. Factors eIF2, eIF3, eIF4A, eIF4B, and eIF4F are sufficient for 48S complex formation on the EMCV IRES (Pestova et al. 1996a) and to a much lesser extent on the TMEV IRES (Fig. 4A, lane 8). This minimal set of five eIFs was not sufficient for $48 \mathrm{~S}$ complex formation on the FMDV IRES (Fig. 3, lane 1; Fig. 5A, lane 3; Fig. 6A,B, lanes 3). PTB is a candidate for the missing essential activity because it binds specifically to the FMDV IRES and enhances its function (Luz and Beck 1990; Niepmann 1995; Kolupaeva et al. 1996). However, inclusion of PTB in reactions with the minimal set of factors did not lead to $48 \mathrm{~S}$ complex formation on GD68 or GD80 mRNAs (Fig. 5C, lane 4; Fig. 6A,B, lanes 4). Internal initiation on the FMDV IRES therefore has different factor requirements than on either EMCV or TMEV IRESs, even though all three are related.

\section{$I_{T A F}$ is a novel trans-acting factor required for initiation on the FMDV IRES}

RRL contains all factors required for FMDV IRES function (Fig. 1; Fig. 3, lane 2) and was therefore used as a source for purification of the additional factor(s) required together with the minimum set of eIFs for $48 \mathrm{~S}$ complex formation. The $0.5 \mathrm{M} \mathrm{KCl}$ ribosomal salt wash (RSW) was divided into $0 \%-40 \%, 40 \%-50 \%, 50 \%-70 \%$, and $70 \%-$ $95 \%$ ammonium sulfate (AS) fractions. Individually, none of these fractions promoted $48 \mathrm{~S}$ complex formation

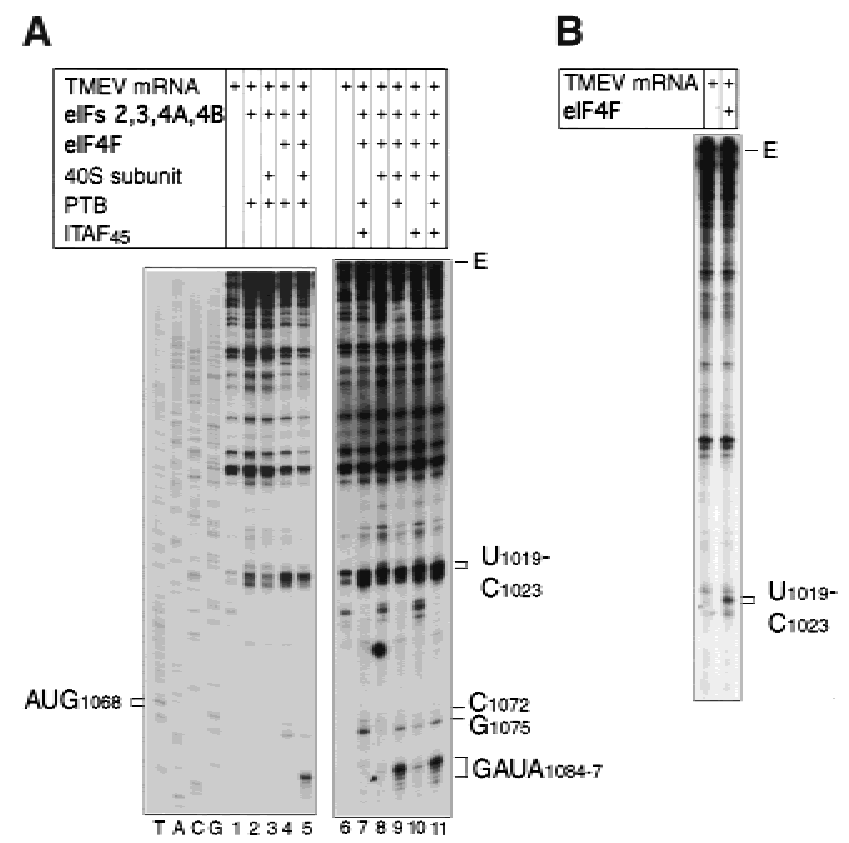

Figure 4. Factor dependence of $48 \mathrm{~S}$ complex formation on the Theiler's murine encephalomyelitis virus (TMEV) internal ribosomal entry site. (A) Toeprinting analysis of RNP and 48S ribosomal complexes assembled on wt TMEV GDVII nt 1-1334 RNA under standard conditions as follows: with aminoacylated initiator tRNA and eIF2, eIF3, eIF4A, and eIF4B (lanes 2-11); with eIF4F (lanes 4-11); with 40S subunits (lanes 3,5,8-11); PTB (lanes 2-5,7,9,11); and $\operatorname{ITAF}_{45}$ (lanes 7,10,11). A primer was annealed within the TMEV coding sequence and was extended with AMV-RT. (B) Toeprinting analysis of the ribonucleoprotein complex assembled by incubating wt TMEV GDVII nt 1-1334 RNA with (lane 2) or without (lane 1) eIF4F. The fulllength cDNA extension product is marked E. Other cDNA products terminated at the sites indicated on the right. Reference lanes $T, A, C$, and $G$ depict the negative-strand TMEV sequence derived using the same primer. 

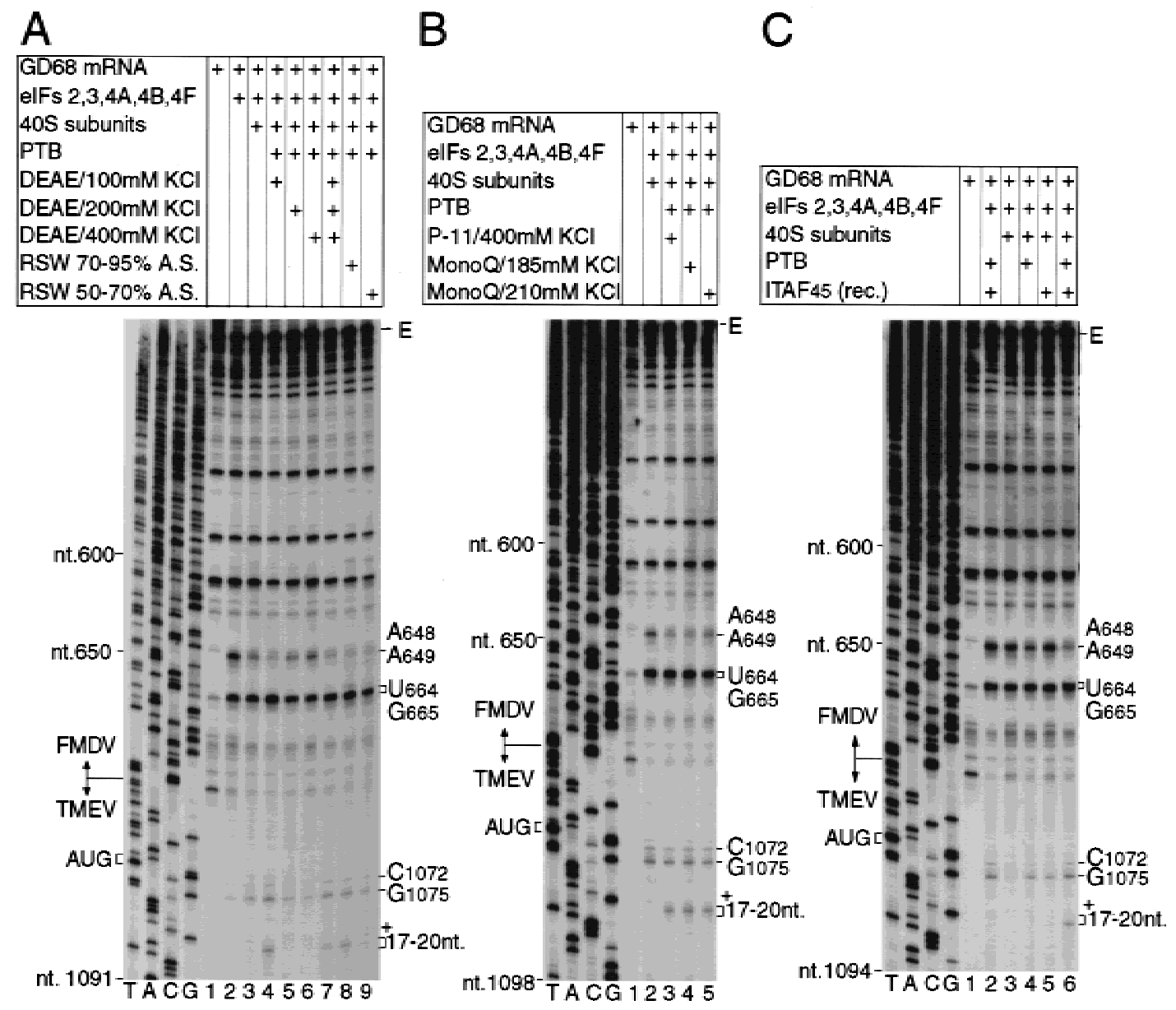

Figure 5. Purification of internal ribosomal entry site (IRES) trans-acting factors from rabbit reticulocyte lysate required for internal ribosomal entry on the foot-and-mouth disease virus (FMDV) $0_{1} \mathrm{~K}$ IRES, using toeprinting to assay $48 \mathrm{~S}$ complex assembly. GD68 mRNA was incubated under standard reaction conditions for assembly of $48 \mathrm{~S}$ complexes with translation components as indicated and (A) with the $70 \%-95 \%$ AS fraction (lane 8 ) or with the 50\%-70\% AS fraction (lane 9) and with the 100 mM KCl DEAE flow-though (lanes 4,7), the 250-mm KCl DEAE elution fraction (lanes 5,7), or the 400-mm DEAE elution fractions (lanes 6,7) of the RSW 70\%-95\% AS fraction; $(B)$ with the 400-mm KCl phosphocellulose elution fraction (lane 3) or with 185-mm KCl (lane 4) or 210-mm KCl (lane 5) MonoQ elution fractions derived from this phosphocellulose elution fraction; and $(C)$ with recombinant PTB $($ lanes $2,4,6)$ and recombinant $\operatorname{ITAF}_{45}$ (lanes 2,5,6). A primer was annealed to Theiler's murine encephalomyelitis virus (TMEV) nt 1195-1214 in the coding region of GD68 mRNA and was extended with AMV-RT. The full-length cDNA extension product is marked E. cDNA products labeled ${ }^{+} 17-{ }^{+} 20 \mathrm{nt}$ terminated at these positions $3^{\prime}$ to the A of TMEV initiation codon. Other cDNA products terminated at the sites indicated on the right. Reference lanes $T, A, C$, and $G$ depict the negative-strand sequence derived using the same primer and GD68 plasmid DNA. The junction between TMEV GDVII and FMDV $0_{1} \mathrm{~K}$ nucleotides and the position of the initiation codon are indicated.

on GD68 mRNA when included with 40S subunits and eIF2, eIF3, eIF4A, eIF4B, and eIF4F. However, a combination of $0 \%-40 \%$ and $70 \%-95 \%$ AS fractions together provided the additional activities necessary for efficient $48 \mathrm{~S}$ complex formation on the FMDV IRES (data not shown).

The active subfractions of the $0 \%-40 \%$ AS fraction were identical to those that contain PTB (Hellen et al. 1994). Recombinant PTB replaced the 0\%-40\% AS fraction without loss of activity in reactions that also contained the $70 \%-95 \%$ AS fraction (Fig. 5A, lane 8; data not shown). PTB is therefore essential for initiation on the FMDV IRES and was included in all subsequent reactions. The active component of the $70 \%-95 \%$ AS fraction was initially purified by DEAE-cellulose chromatog- raphy (Fig. 7A). The active $100 \mathrm{~mm} \mathrm{KCl}$ flow-through fraction (Fig. 5A, lane 4) was applied to a phosphocellulose column, and proteins in it were separated by stepelution. The IRES trans-acting factor was in the 250400-mm KCl fraction (Fig. 5B, lane 3), which was dialysed against $50 \mathrm{~mm} \mathrm{KCl}$ buffer, applied to an FPLC MonoQ column and eluted with a $50-500 \mathrm{~mm} \mathrm{KCl}$ gradient. Two well-resolved major peaks that eluted with $185 \mathrm{~mm}$ and $210 \mathrm{~mm} \mathrm{KCl}$ both contained nearly homogenous $45-\mathrm{kD}$ proteins (e.g., Fig. 7B). The former peak was half as large as the latter. The electrophoretic mobility and the activity of these proteins were identical (Fig. 5B, lanes 4,5). We named this protein IRES trans-acting factor 45 $\left(\mathrm{ITAF}_{45}\right)$ on the basis of its function and apparent molecular weight. $\mathrm{ITAF}_{45}$ and the minimum set of eIFs 
Figure 6. Identical activities of native and recombinant $\mathrm{ITAF}_{45}$ in foot-and-mouth disease virus internal-ribosomal-entry-site-mediated translation initiation. Toeprinting analysis of $48 \mathrm{~S}$ and RNP complexes assembled on GD80 mRNA under standard conditions for assembly of $48 \mathrm{~S}$ complexes as follows: with aminoacylated initiator tRNA and eIFs eIF2, eIF3, eIF4A, eIF4B, and eIF4F (lanes 2-6) with 40S subunits (lanes 3-6), recombinant PTB-1 (B) recombinant $\mathrm{His}_{6}-\mathrm{ITAF}_{45}$ (lanes 2,5,6). A primer was annealed to Theiler's murine encephalomyelitis virus nt 1195-1214 of GD80 mRNA and was extended with AMV-RT. The full-length cDNA extension product is marked E. Other cDNA products terminated at sites indicated on the right of each panel. Reference lanes $T, A, C$, and $G$ depict the negative-strand sequence derived using the same primer and GD80 plasmid DNA. The position of the initiation codon is indicated. (lanes 2,4,6) and $(A)$ native $\operatorname{ITAF}_{45}($ lanes 2,5,6) or
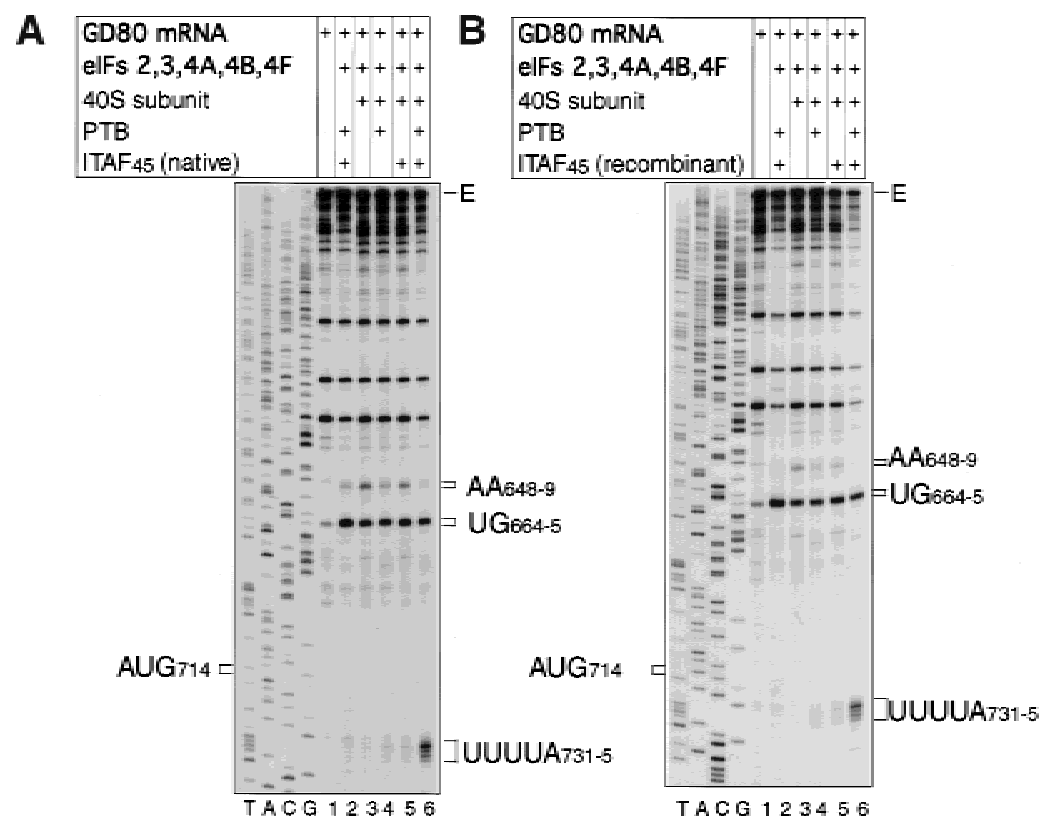

without PTB were not sufficient to mediate $48 \mathrm{~S}$ complex formation on GD68 mRNA (Fig. 5C, lane 5). Initiation on the FMDV IRES therefore requires both PTB and $\mathrm{ITAF}_{45}$. Separation of $\mathrm{ITAF}_{45}$ into two populations suggests that it may be modified posttranslationally.

GD68 contains FMDV IRES sequences to the middle of the pyrimidine tract followed by TMEV nucleotides (Fig. 1). To confirm that initiation on the FMDV IRES requires both $\mathrm{PTB}$ and $\mathrm{ITAF}_{45}$ in addition to canonical eIFs, 48S complexes were also assembled on GD80 mRNA, which contains FMDV IRES sequences up to and including the initiation codon $\mathrm{AUG}_{714-6}$ and eight additional codons. PTB and $\mathrm{ITAF}_{45}$ were both required, along with the minimum set of eIFs for $48 \mathrm{~S}$ complex assembly on this mRNA, yielding prominent toeprints at positions 18-22 nt 3' of the A of $\mathrm{AUG}_{714}$ (Fig. 6A, lanes 3-6). 48S complex formation was absolutely dependent on MettRNA $^{\text {Met }}{ }_{i}$, eIF2, eIF3, eIF4F, and 40S subunits but did not require eIF1 or eIF1A (data not shown).

Inclusion of $\mathrm{ITAF}_{45}$ in $48 \mathrm{~S}$ complex assembly reactions on wt TMEV GDVII mRNA confirmed that ITAF $_{45}$ could not substitute for PTB in this process and did not alter the pattern or intensity of toeprints caused by bound 48S complexes or by bound eIF4F (cf. Fig. 4A, lanes 9-11). These results confirm that initiation on the TMEV IRES requires PTB and show that the additional requirement for $\mathrm{ITAF}_{45}$ is specific for FMDV. This conclusion was supported by the observation that recombinant $\mathrm{ITAF}_{45}$ did not influence initiation on either the EMCV IRES or on capped native globin mRNA (data not shown).

\section{Molecular cloning of ITAF 45}

The identity of ITAF $_{45}$ was determined by amino acid sequence analysis. The amino terminus of $\mathrm{ITAF}_{45}$ was blocked (data not shown). The sequences of two wellresolved tryptic peptides from $\mathrm{ITAF}_{45}$ were LVKPGNQNTQVTEAWNK and RRFDAMPFTLR. They correspond exactly to amino acids $156-172$ and $271-281$ of murine proliferation-associated protein $(M p p 1$; Nakagawa et al. 1997) and PAG24, its human homolog (Lamartine et al. 1997), as well as to sequences of p38-2G4, a possible smaller $(37 \mathrm{kD})$ murine $M p p 1$ isoform (Radomski and Jost 1995).

To confirm that $\mathrm{ITAF}_{45}$ and $M p p 1$ are the same protein and that it plays a specific role in FMDV IRES-mediated initiation, cDNA for this protein was amplified by PCR, cloned, and sequenced. The single long ORF encodes a 394 amino acid protein with a calculated molecular mass of 43,669 Daltons. This value is in agreement with that estimated for $\mathrm{ITAF}_{45}$ by SDS-PAGE. The $\mathrm{ITAF}_{45} \mathrm{cDNA}$ sequence differed from that of $M p p 1$ at two nucleotides, both of which resulted in coding changes $\left(\mathrm{A}_{279}\right.$ and $\mathrm{R}_{311}$ in $\mathrm{ITAF}_{45}$ in place of $\mathrm{T}_{279}$ and $\mathrm{K}_{311}$ in $\mathrm{Mpp} 1$ ). As reported previously for Mpp1 and p38-2G4, homologous proteins of a similar size occur in many eukaryotes. These range from the closely related PAS1 protein from Fugu ribripes to a more distantly related DNA-binding protein from Schizosaccharomyces pombe (Yamada et al. 1994; Gellner and Brenner 1999). Significant sequence homologies also exist between these proteins, $\mathrm{ITAF}_{45}$, and type II methionine aminopeptidases from archaea and eukaryotes (Fig. 7C,D). These similarities extend over the entire $\mathrm{ITAF}_{45}$ coding sequence and include four of the five signature amino acid residues that coordinate two cobalt ions in these metallo-enzymes (Tahirov et al. 1998). This group of enzymes includes p67, a methionine aminopeptidase that regulates translation by interacting with the $\gamma$ subunit of eIF2 and inhibiting phosphorylation of its $\alpha$ subunit (Ray et al. 1993; Arfin et al. 1995). ITAFs such as PTB, PCBP2, and unr are, respectively, RNP-motif, KH- 
a

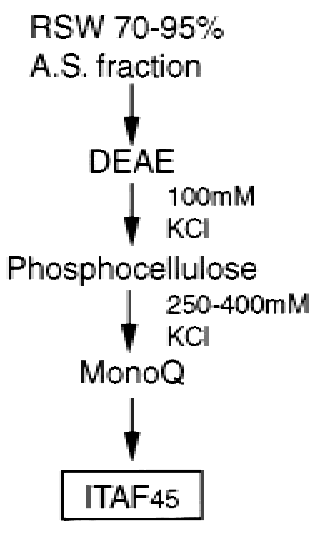

b

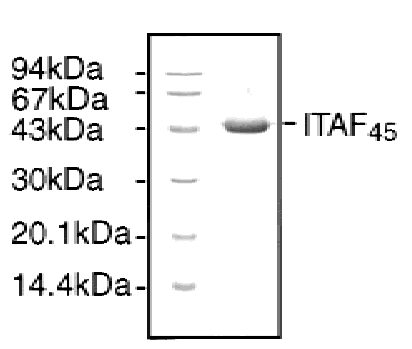

C

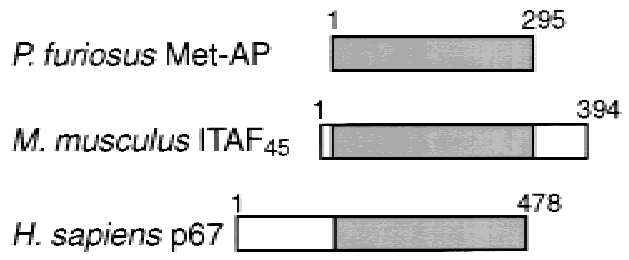

d

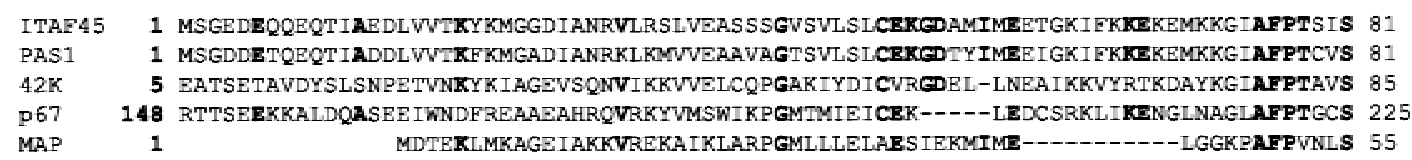

ITAF45 81 VNNCVCHFSPLKSDQD--YILREGLVRIDLGVHVDGFIANVAHTFVIGVAQGTQVTGRKADVIKAAHLCAEAALRLVKPG 160 PAS1 81 VNNCVCHFSPVKSDEN--VILKOGDLVIDIGVHVDGFISNVAHSLIVGVTKDNPQTGRKADLMMAAHLCAFAAIRLVKPG 160 42K 86 PNDNAAHLSPLKSDPEANLALKSEDVVKILLGAHIDGFASLVATTTVVSEBP---VTGPAADVIAAASAALKAAGRTIKPG 165 p67 226 LNNCAAHYTPNAGDTT---VLQYDDICKIDFGTHISGRIIDCAFTVTFNPKYDILLKAVK-DATNTGIKCAGIDVRLCDVG 301 MAP 56 INEIAAHYTPYKGDTT---VLREGYLIDVGVHIDGFIADTAVTVRVGMEDD--------ELMEAAKEALNAAISVARAG 126

ITAF45 161 NQNTQVTEAWN-KV-AHSFNCTPIEGMLSHQLKQHVIDGEKTIIQNPTDQQKKDHEKAEFEVHIVYAVDVLVS-SGEGKAK 238 PAS1 161 NQNTQVTEAWN-KI-AKSEKCAPIEGMLSHQLKQHVIDGEKTI IQNPTDQQKKDHEKAEEEVHSVYAVDVLIS-7GEGKAK 238 42K 166 NTNAQVTDIVD-K--ATSYGCKPVAGMLSHQQEREVIDGKKQVIINPSDSQRSEMDTFTEZEGEVYGVDILVSTSPSGKVK 239 p67 302 EAIQEVMESYEVEIDGKTYQVKPIRNLNGHSIGPYRIHAGKTV---PI---VKGGEATRMREGEVYAIETFGS-TGKGVVH 375 MAP 127 VEIKELGKAIENEI-RKRGFÓKPIVNLSGHKIERYKLHAGISI---PN--IYRPHDNYVLKEGDVFAIEPFAS-IGAGQVI 199

ITAF45 239 DAGQRTTIYKRDPSKQYGLKMKTSRAFFSEVERRFDAMPFALRAFED---EKKARMGVVECAKHELLQPFNVLYEREGEEV 316 PAS1 239 DGGQRTTVYKRDPNKVYGLKMKSSRYLFSDIERRFDTMPFTLRAFEE---ESKARLGLVECAKHELLQPETVLYEKEGEEV 316 42K 240 RSDIATRIYKKTDT-YMLKLOASRKVYSEIQTKFGPFPFSTRNIS----EDSRTNMGNECTSHKLLFPYEVLLDKDGGIV 315 p67 376 DDMECSHYMKNFDVGHVPIRLPRTKHLLNVINENFGTLAFCRRWLDRL-GESKYLMALKNLCDLGIVDPYPPLCDIKGSYT 475 MAP 200 EVPP-TLIYMY--VRDVPVRVAQARFLLAKIKREYGTLPFAYRWLQNDMPEGQLKLALKTLEKAGAIYGYPVLKEIRNGIV 276

\begin{tabular}{|c|c|c|}
\hline $17 A F 45$ & 317 & $E$ \\
\hline PAS1 & 317 & AQFKETVLLMANGPLRITNSLFDPDLYKSEYKVEDPELKNLLQSSA-SRKTCKKKKKKASKNAESAT-GQANZTEAAE \\
\hline $42 \mathrm{~K}$ & 316 & ARFYSTIALTKKGTI ILSDSE PKEDF IKSDKKVEDPEIVALLETPIK-VTKNKKKKSKKPSKANE \\
\hline $\mathrm{p} 67$ & 476 & AQFEHTILLRPTCKEVVSRGDDY \\
\hline MAP & 277 & AOREHTI IVEKDSVIVTTE \\
\hline
\end{tabular}

Figure 7. Purification and structure of $\operatorname{ITAF}_{45} .(A)$ Scheme for the purification of $\mathrm{ITAF}_{45}$ from the $0.5 \mathrm{M} \mathrm{KCl} \mathrm{RSW} \mathrm{from} \mathrm{RRL.}(B)$ Resolution by SDS-PAGE of native rabbit $\mathrm{ITAF}_{45}(2 \mu \mathrm{g})$ after purification by MonoQ chromatography and elution with $210 \mathrm{~mm} \mathrm{KCl}$. The positions of molecular weight markers are indicated to the left and those of $\mathrm{ITAF}_{45}$ to the right. $(C)$ Schematic illustration of ITAF $_{45}$ with p67 and MAP to show regions of homology. $(D)$ Deduced amino acid sequence of ITAF 45 and alignment of it with sequences of the PAS1 protein from Fugu ribripes (PAS1; Gellner and Brenner 1999), p42 protein from Schizosaccharomyces pombe (p42; Yamada et al. 1994), and with type II methionine aminopeptidases from human (p67; Arfin et al. 1995) and from the hyperthermophile Pyrococcus furiosus (MAP; Tahirov et al. 1998). The sequences of these proteins and $\operatorname{ITAF}_{45}$ show $71 \%, 26 \%, 23 \%$, and $35 \%$ amino acid identity and $80 \%, 44 \%, 43 \%$, and $48 \%$ similarity, respectively. Residues in bold are present in the majority of sequences and have been introduced to facilitate visualization of alignments.

domain, and cold shock domain proteins, but $\mathrm{ITAF}_{45}$ does not belong to any of these recognized families of RNA-binding proteins.

To confirm that the IRES-trans-activating activity of $\mathrm{ITAF}_{45}$ is not due to a contaminant, recombinant His $_{6}{ }^{-}$ $\mathrm{ITAF}_{45}$ was purified to homogeneity and its activity assayed in assembly reactions done on GD80 mRNA. Inclusion of PTB and $\mathrm{His}_{6}-\mathrm{ITAF}_{45}$ or native $\mathrm{ITAF}_{45}$ together with the minimum set of eIFs led to the formation of prominent $48 \mathrm{~S}$ complexes that yielded identical toeprint patterns (Fig. 6A,B, lane 6). Significant assembly of $48 \mathrm{~S}$ complexes on this mRNA did not occur unless PTB and $\mathrm{ITAF}_{45}$ were present together (Fig. 6A,B, lanes 3-6). Native and recombinant ITAF $_{45}$ therefore have identical activities.

Ribosomal complexes assembled in these reactions were also resolved from RNP complexes by sucrose density gradient centrifugation to verify that they corre- 
Pilipenko et al.

Figure 8. Dependence of foot-and-mouth disease virus (FMDV) internal-ribosomalentry-site (IRES)-mediated internal ribosomal entry on PTB and ITAF $_{45}$, assayed by sucrose-density gradient centrifugation. Assays were carried out under standard conditions using GD68 or GD80 nt 1-1334 mRNA as indicated. Assembly reactions contained eIFs eIF2, eIF3, eIF4A, eIF4B, and eIF4F, and included recombinant PTB-1 and/or His $_{6}-\mathrm{ITAF}_{45}$, as indicated. Sedimentation was from right to left. Fractions from the upper part of the sucrose gradient were omitted for clarity.

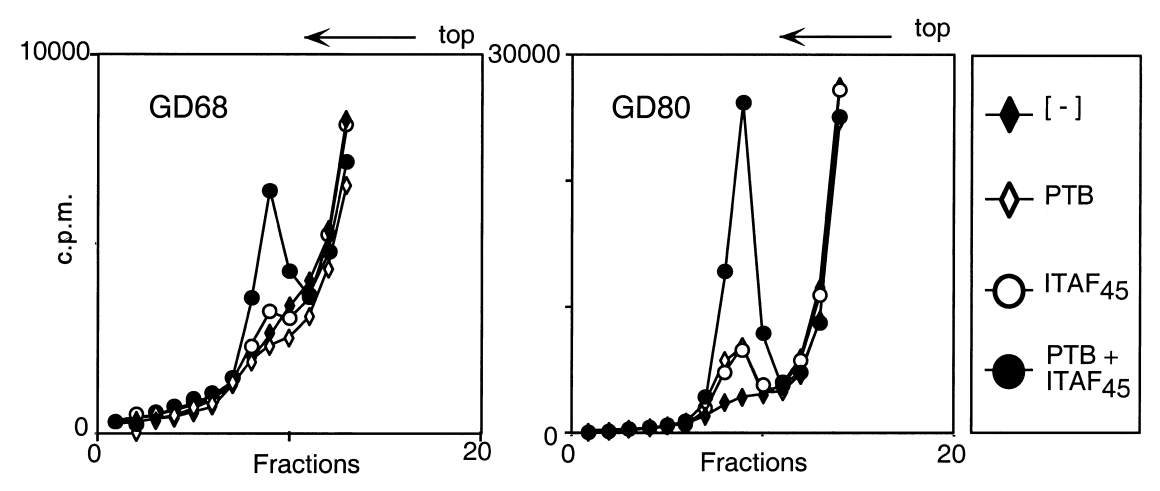

spond to authentic $48 \mathrm{~S}$ complexes and to confirm the factor requirements for their formation. $48 \mathrm{~S}$ complexes were formed on GD68 mRNA in reactions that contained eIF2, eIF3, eIF4A, eIF4B, and eIF4F only if both PTB and His $_{6}-\mathrm{ITAF}_{45}$ were present but not if either or both were omitted (Fig. 8). In parallel experiments done using GD80 mRNA, eIF2, eIF3, eIF4A, eIF4B, and eIF4F were not sufficient to mediate efficient $48 \mathrm{~S}$ complex formation (Fig. 8). Inclusion of either $\mathrm{ITAF}_{45}$ or PTB individually in reactions containing these eIFs yielded small amounts of $48 \mathrm{~S}$ complex. Inclusion of $\mathrm{ITAF}_{45}$ and PTB together in reactions had a very strong synergistic effect on $48 \mathrm{~S}$ complex assembly (Fig. 8). These observations are exactly consistent with the results noted previously for assembly reactions on this mRNA assayed by toeprinting. Taken together, the results obtained using recombinant PTB and $\mathrm{ITAF}_{45}$ confirm that these two trans-acting factors both are necessary and are together sufficient for assembly of $48 \mathrm{~S}$ complexes on the FMDV IRES in the presence of eIF2, eIF3, eIF4A, eIF4B, and eIF4F.

\section{UV cross-linking of ITAF 45}

The role of $\mathrm{ITAF}_{45}$ in promoting initiation on the FMDV IRES could involve specific binding to it. A UV crosslinking assay was used to investigate whether $\mathrm{ITAF}_{45}$ is a specific RNA-binding protein (Fig. 9A). $\mathrm{ITAF}_{45}$ was labeled significantly more strongly after UV cross-linking to $\left[{ }^{32}\right.$ P]UTP-labeled nt 1-1334 GD80 mRNA (which contains the FMDV IRES) than to $\beta$-globin mRNA (Fig. 9A, lanes 1,5 ), both in the presence of a 50-fold molecular weight excess of unlabeled tRNA. Native $\mathrm{ITAF}_{45}$ was as strongly labeled after UV cross-linking to $\left[{ }^{32} \mathrm{P}\right] \mathrm{UTP}-\mathrm{la}-$ beled wt TMEV nt 1-1334 RNA as to the equivalent chimeric GD80 RNA (Fig. 9A, lanes 1,3). The interaction of ITAF $_{45}$ with wt TMEV and chimeric GD80 RNAs was specific since it was not significantly affected by the additional inclusion in cross-linking assays of a 15 -fold molecular weight rRNA excess, where UV cross-linking of $\mathrm{ITAF}_{45}$ to $\beta$-globin RNA was slightly reduced by this competitor (Fig. 9A, cf. lanes 1,3,5 with lanes 2,4,6). Labeling of recombinant and native forms of $\mathrm{ITAF}_{45}$ after UV cross-linking to $\left[{ }^{32} \mathrm{P}\right] \mathrm{UTP}-\mathrm{labeled} w t \mathrm{TMEV}$ and chi- meric GD80 nt 1-1334 RNAs was comparable and was equally resistant to challenge by tRNA/rRNA competitors (Fig. 9B). In parallel experiments, recombinant and native $\mathrm{ITAF}_{45}$ also became strongly labeled after UV cross-linking to the EMCV IRES (data not shown). The interaction of $\mathrm{ITAF}_{45}$ with these RNAs is therefore specific and not caused by contaminants in preparations of the native protein.

Interactions of initiation factors with the FMDV IRES assayed by toeprinting

IRES-mediated initiation involves specific interactions between the IRES and the components of the translation apparatus. We used toeprinting and footprinting to map the interactions of factors with the FMDV IRES. The presence of eIF2, eIF3, eIF4A, eIF4B, and eIF4F in assembly reactions on the FMDV IRES of GD68 mRNA with or without $40 \mathrm{~S}$ subunits enhanced a toeprint at

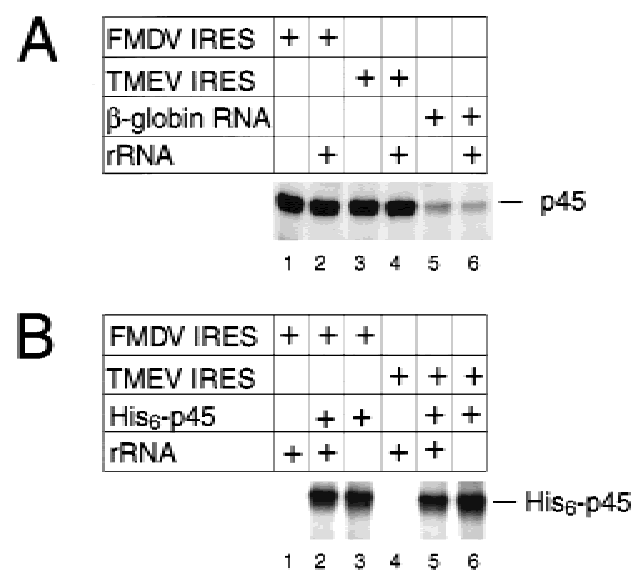

Figure 9. UV cross-linking of ITAF $_{45}$ to wt Theiler's murine encephalomyelitis virus (TMEV) GDVII, chimeric foot-andmouth disease virus (FMDV)/TMEV GD80 and $\beta$-globin mRNAs. (A) Native and $(B)$ recombinant $\mathrm{ITAF}_{45}$ were UV crosslinked to $\left[{ }^{32} \mathrm{P}\right] \mathrm{UTP}-\mathrm{labeled} w t$ TMEV GDVII nt 1-1334, chimeric FMDV/TMEV GD80 nt 1-1334 or $\beta$-globin RNA nt 1-600 RNAs in the presence of a $50 \times$ molecular weight excess of tRNA and in the presence or absence a $15 \times$ molecular weight excess of ribosomal RNA, as indicated. 
$\mathrm{U}_{664}$ and led to the appearance of prominent new toeprints at $\mathrm{AA}_{648-9}$ and $\mathrm{G}_{665}$ (e.g., Fig. 5C, lanes 1-3). Similar toeprints appeared on GD80 mRNA in the presence of these factors (Fig. 6A,B, lanes 1-3). $\mathrm{UG}_{664-5}$ and $\mathrm{AA}_{648-9}$ map to the base of the $\mathrm{J}_{1}$ and $\mathrm{K}_{1}$ helices of the $\mathrm{J}-\mathrm{K}$ domain, respectively (Fig. $2 \mathrm{~B})$, and correspond to the binding site for the eIF4G subunit of eIF4F on EMCV and TMEV IRESs (Figs. 4B, 2A; Pestova et al. 1996a,b; Kolupaeva et al. 1998). The prominence of the $\mathrm{AA}_{648-9}$ toeprints was reduced on GD68 and more strongly on GD80 mRNA on inclusion of PTB in assembly reactions, and more strongly on inclusion of $\mathrm{ITAF}_{45}$ with PTB (Fig. 5C, lanes 3-6; Fig. 6A,B, lanes 3-6), implying some changes in the conformation of the IRES or in the character of its interaction with eIF4F as a result of binding PTB and $\mathrm{ITAF}_{45}$. Binding of eIFs to GD68 mRNA yielded weak toeprints at $C_{1072}$ and $G_{1075}$ (e.g., Fig. 5C, lane 3) that were previously detected on GDVII RNA (Fig. 4A). These toeprints resulting from binding of the eIF4A/ eIF4G complex to the IRES are markedly enhanced in the presence of PTB or ITAF $_{45}$ individually and are enhanced to an even greater extent on inclusion of PTB and $\mathrm{ITAF}_{45}$ together (Fig. 5C, lanes 2,6). We do not know whether these toeprints are indicative of conformational changes in the IRES or whether they represent additional contacts of the IRES with the eIF4G/4A complex. In any case, enhancement of these toeprints in the presence of PTB and $\mathrm{ITAF}_{45}$ indicates that these two proteins may facilitate binding of the eIF4G/4A complex to the IRES, which might in turn enhance $48 \mathrm{~S}$ complex formation.

Toeprint analysis of RNP complexes formed with different combinations of factors indicated that eIF4F bound specifically to the FMDV IRES, yielding toeprints at $\mathrm{UG}_{664-5}$ in the J-K domain (data not shown). More detailed analysis indicated that the central domain of eIF4G (residues 607-1076) bound specifically but weakly to the FMDV IRES, yielding a toeprint at $\mathrm{G}_{665}$ (Fig. 10A, lanes 1,2). Inclusion of eIF4A with eIF4 $\mathrm{G}_{607-1076}$ resulted in the appearance of an additional toeprint at $\mathrm{U}_{664}$ (Fig. 10A, lanes 2,3). eIF4A alone did not lead to the appearance of toeprints anywhere on the IRES (data not shown). The intensity of the $\mathrm{G}_{665}$ toeprint due to bound eIF4G $\mathrm{G}_{607-1076}$ and of the $\mathrm{UG}_{664-5}$ toeprints due to the bound eIF4A/eIF4G ${ }_{607-1076}$ complex were enhanced by PTB and $\mathrm{ITAF}_{45}$ individually and together (Fig. 10A, lanes 1-9). Inclusion of PTB in these reactions led to the appearance of toeprints at GCCG $_{681-4}$ and $\mathrm{UUU}_{690-2}$ that did not depend on the presence of other factors, including eIF4G, eIF4A, eIF4B, and $\operatorname{ITAF}_{45}$ (Fig. 2; Fig. 10A, lanes 1,4,6,7,9,10; Fig. 10B, lanes 1,4$)$. The toeprints at $\mathrm{UUU}_{690-2}$ correspond to residues that are protected by PTB from chemical modification (Kolupaeva et al. 1996). Toeprints appeared at $\mathrm{GU}_{671-2}$ on inclusion of PTB and $\mathrm{ITAF}_{45}$ in binding reactions only in the presence of eIF4G $\mathrm{G}_{607-1076}$ (cf. Fig. 10A, lane 6 and Fig. 10B, lane 4). Taken together, these observations indicate that the specific binding of eIF4G to the FMDV J-K domain is enhanced by eIF4A, PTB, and $\mathrm{ITAF}_{45}$.
A

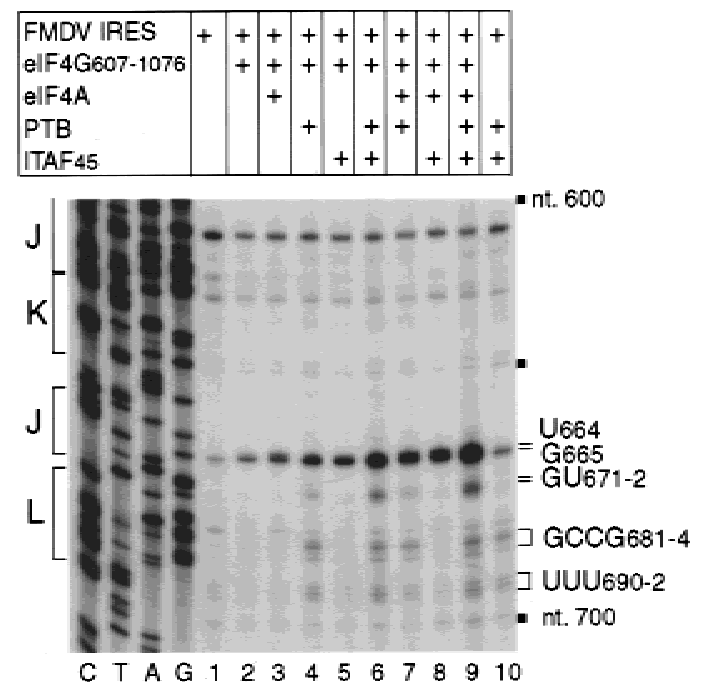

B

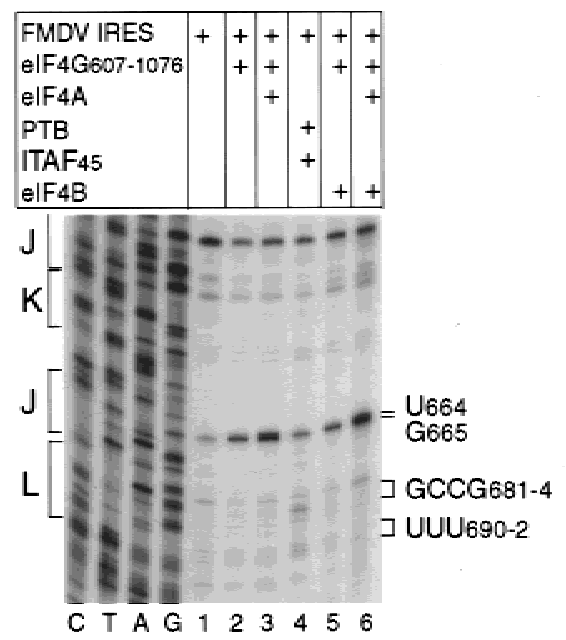

Figure 10. $(A, B)$ Primer extension analysis of a ribonucleoprotein complex formed on the foot-and-mouth disease virus (FMDV) internal ribosomal entry site (IRES). GD80 mRNA was incubated under standard conditions with $\mathrm{ITAF}_{45}, \mathrm{PTB}$, eIF4A, eIF4B, and eIF4 $\mathrm{G}_{607-1076}$ individually or in combination as indicated. An oligonucleotide was annealed within the coding sequence and extended with AMV-RT. The cDNA products labeled $\mathrm{U}_{664}, \mathrm{G}_{6655}, \mathrm{GU}_{671-2}, \mathrm{GCCG}_{681-4}$, and $\mathrm{UUU}_{690-2}$ terminated at these nucleotides. Reference lanes $C, T, A$, and $G$ depict the negative strand FMDV sequence.

\section{Localization of factor-binding sites on the FMDV IRES} by footprinting

Footprinting was used to map binding sites for eIFs, PTB, and ITAF $_{45}$ on the FMDV IRES and to identify structural changes in it caused by their binding. In these experiments we used RNase $T_{1}$ (which cleaves RNA specifically after unpaired G residues) and 1-cyclohexyl-3-(2morpholinoethyl)-carbodiimide metho-p-toluene sulphate (CMCT), which reacts with N-3 of unpaired uracil and N-1 of unpaired guanine residues (Ehresmann et al. 1987). Chemical modification or strand scission both arrest reverse transcriptase and can thus be analyzed by 
primer extension. CMCT modification causes primer extension arrest at the nucleotide immediately $3^{\prime}$ to the modified position, and enzymatic cleavage results in arrest of primer extension at the nucleotide on the 3 '-side of the cleaved bond. Some residues in the FMDV IRES at which cleavage or modification patterns appear to be altered in the presence of factors such as $\mathrm{G}_{401}$ coincide with strong stops formed during primer extension on this highly structured RNA. Altered cleavage or modification of such residues is therefore equivocal and is not discussed below. Results of this analysis are summarized in Fig. 12 (see below).

Individually, neither eIF4A nor eIF4G $607-1076$ protected any part of the IRES from cleavage or modification (Fig. 11A, lanes 4,7; data not shown). However, together they specifically protected the IRES from cleavage at $\mathrm{G}_{569}, \mathrm{G}_{611}$, and $\mathrm{G}_{653}$ in the J-K domain and at $\mathrm{GG}_{670-1}$ and $\mathrm{G}_{673}$ in domain $\mathrm{L}$ (Fig. 11A, lane 5). These results are consistent with the results of toeprinting (Fig. 10A) and with the identification of eIF4G binding sites at identical locations in EMCV and TMEV IRESs.

PTB alone protected the FMDV IRES from cleavage at $\mathrm{G}_{317}$ in domain $\mathrm{H}$ (Fig. 11C, lane 3) and at $\mathrm{GG}_{670-1}$ and $\mathrm{G}_{673}$ in domain L (Fig. 11A, lane 3). The protected site in domain $\mathrm{H}$ is very close to residues in its apical loop that are protected by PTB from CMCT modification (Kolupaeva et al. 1996; Fig. 12). PTB alone also enhanced cleavage at $\mathrm{GG}_{680-1}$ at the apex of domain $\mathrm{L}$ and, weakly, at $\mathrm{G}_{569}$ at the junction of domains J and $\mathrm{K}$ (Fig. 11A, line 3). Binding of $\mathrm{ITAF}_{45}$ alone to the IRES protected it from cleavage at $\mathrm{G}_{351}$ in the basal part of domain I (Fig. 11C, lanes 2,5; Fig. 12) and enhanced CMCT modification at $\mathrm{G}_{491}$ in the apical half of domain $\mathrm{I}$ and at $\mathrm{U}_{554}, \mathrm{U}_{672}$, $\mathrm{G}_{678}$, and $\mathrm{G}_{685}$ near and within domain L (Fig. 11D, lane 2). Taken together, the data indicate that PTB and $\mathrm{ITAF}_{45}$ interact functionally with the IRES at several specific sites and may therefore act as RNA chaperones that foster correct IRES folding. Importantly, the footprint pattern caused by binding of PTB and ITAF $_{45}$ together to the IRES differed somewhat from the summation of the footprints caused by binding of these two proteins individually. Thus, PTB alone enhanced RNase $\mathrm{T}_{1}$ cleavage at $\mathrm{G}_{355}$, near the base of domain $\mathrm{I}$, and this enhanced cleavage was suppressed by $\operatorname{ITAF}_{45}$ (Fig. 11C, lanes 3,4). A combination of PTB and $\mathrm{ITAF}_{45}$ enhanced cleavage at $\mathrm{G}_{491}, \mathrm{G}_{553}$, and $\mathrm{G}_{555}$ and exposed a cleavage site at $\mathrm{G}_{665}$ (Fig. 11B, lane 2). These results are indicative of a cooperative chaperone-like action of PTB and ITAF in RNA recognition and folding, and are consistent with and can account for the synergistic enhancement by these two proteins of $48 \mathrm{~S}$ complex formation on the FMDV IRES.

The strong protection of the FMDV IRES from cleavage at nt 670-673 caused by the binding of eIF4G ${ }_{607-1076}$ eIF4A, PTB, and $\mathrm{ITAF}_{45}$ is consistent with the appearance of additional toeprints at $\mathrm{GU}_{671-2}$ on the IRES on inclusion of both PTB and $\mathrm{ITAF}_{45}$ with either eIF4G $\mathrm{G}_{607-1076}$ or, to a greater extent, with both eIF4G $607-1076$ and eIF4A (Fig. 10A, lanes 2,4-6,10).

The results of footprinting and toeprinting are thus wholly consistent. They indicate that $\operatorname{ITAF}_{45}$ binds at the base of domain I; that PTB makes multiple contacts with the IRES in domain $\mathrm{H}$, domain $\mathrm{K}$, and downstream of domain $\mathrm{L}$; and that the eIF4G/eIF4A binary complex binds to the J-K domain. eIF4A does not bind specifically or stably to the IRES except in the presence of eIF4G. PTB and ITAF $_{45}$ also increase the susceptibility of the IRES to cleavage at several positions by inducing conformational changes in it and synergistically enhance binding of the eIF4G/eIF4A complex in a manner that may account for the dependence of FMDV IRES function on PTB and $\mathrm{ITAF}_{45}$.

\section{Discussion}

We report here that we have identified a cellular RNAbinding protein, $\mathrm{ITAF}_{45}$, that mediates mRNA-selective translation initiation. We identified $\mathrm{ITAF}_{45}$ by reconstituting $48 \mathrm{~S}$ complex formation in vitro on FMDV and TMEV IRESs, using fully fractionated translation components. Initiation on these IRESs and the related EMCV IRES required the same set of canonical eIFs, but they had strikingly different ITAF requirements. TMEV IRES function was enhanced fivefold by PTB, but initiation on the FMDV IRES was dependent on $\mathrm{ITAF}_{45}$ as well as on PTB. EMCV IRES function did not depend on either of these ITAFs.

\section{The role of canonical initiation factors in internal ribosomal entry}

The canonical factors eIF2, eIF3, eIF4A, eIF4B, and eIF4F are required for $48 \mathrm{~S}$ complex formation on TMEV and FMDV IRESs just as for initiation on the EMCV IRES (Pestova et al. 1996a). Significantly, we found that eIF4F binds specifically to an analagous site in the J-K domains of each of these IRESs (Fig. 4; Pestova et al. 1996a,b; Kolupaeva et al. 1998). The specificity of binding to each of these IRESs is due to its eIF4G subunit. We noted that inclusion of eIF4A with eIF4G in toeprinting assays strongly enhanced its binding to the FMDV IRES and led to the appearance of a new toeprint at $\mathrm{U}_{664}$. Moreover, individually neither eIF4A nor eIF4G protected any part of the IRES from cleavage or chemical modification in footprinting assays. Taken together, these results indicate that the eIF4G/4A complex rather than eIF4G alone is responsible for recognition of the FMDV IRES. This conclusion is consistent with our finding that the affinity of eIF4G for the EMCV IRES is enhanced by up to two orders of magnitude by eIF4A (Lomakin et al. 2000). There is no eIF4E requirement for this interaction or for 48S complex formation. The IRES-eIF4G/4A interaction is essential for initiation; mutations in either the $\mathrm{J}-\mathrm{K}$ domain of these IRESs or in the IRES-binding domain of eIF4G that abrogate this interaction also abrogate IRES function (Pestova et al. 1996a; T.V. Pestova and E.V. Pilipenko, unpubl.). The central domain of eIF4G contains binding sites for eIF4A and eIF3 (Morino et al. 2000) and is presumed to coordinate their activities. In the context 
A
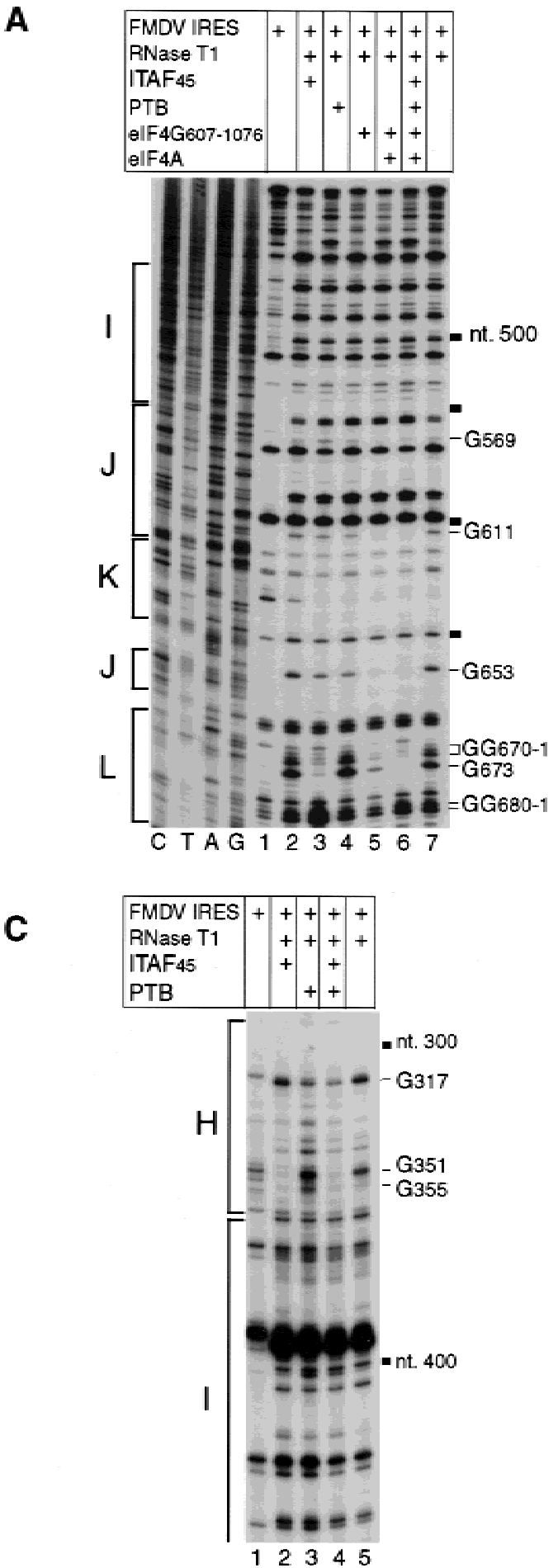

B
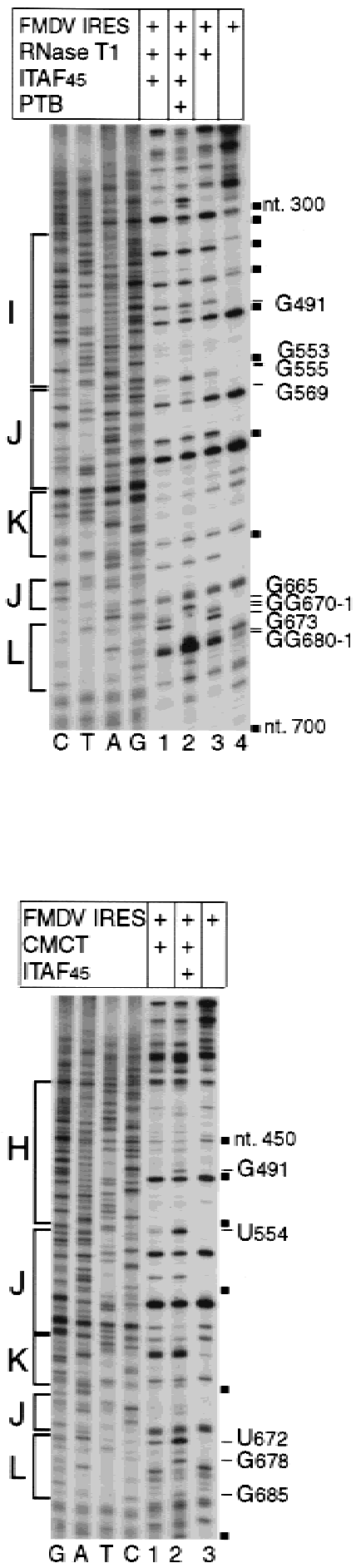

Figure 11. Chemical and enzymatic footprinting of the foot-and-mouth disease virus (FMDV) internal ribosomal entry site (IRES) in complexes formed with the IRES and $\mathrm{ITAF}_{45}, \mathrm{PTB}$, eIF4A, eIF4B, and eIF4G $607-1076$ individually or in combination as indicated. Polyacrylamide-urea gel fractionation of cDNA products obtained after primer extension showing the sensitivity of the internal ribosomal entry site to RNase $\mathrm{T}_{1}$ cleavage $(A$, lanes $2-7 ; B$, lanes $1-3 ; C$, lanes 2-5) and to CMCT modification $(D$, lanes 1,2$)$ either alone or complexed with factors as indicated. cDNA products derived from untreated RNA are shown in lane 1 of panels $A$ and $C$, in lane 4 of panel $B$, and in lane 3 of panel $D$. A dideoxynucleotide sequence generated with the same primer was run in parallel on each gel and is shown in panels $A, B$, and $D$. The positions of protected residues or enhanced cleavage are indicated to the right of each panel. The positions of FMDV nucleotides at 50-nt intervals are indicated by black squares to the right of each panel. Individual subdomains are indicated to the left of each panel. 
Pilipenko et al.

A

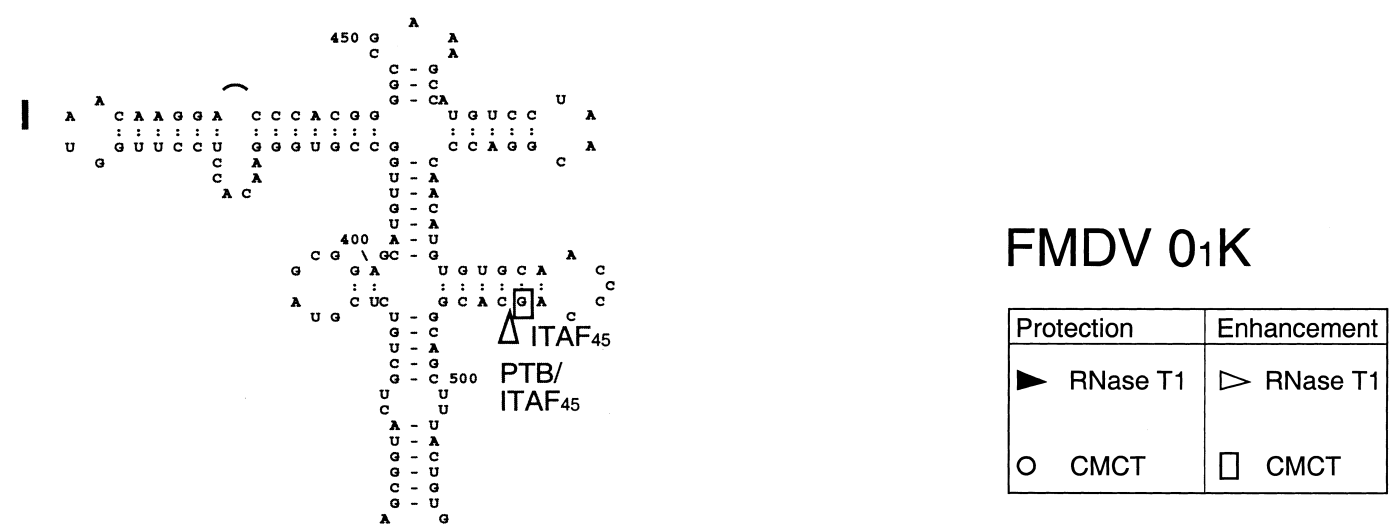

FMDV $0{ }_{1} \mathrm{~K}$
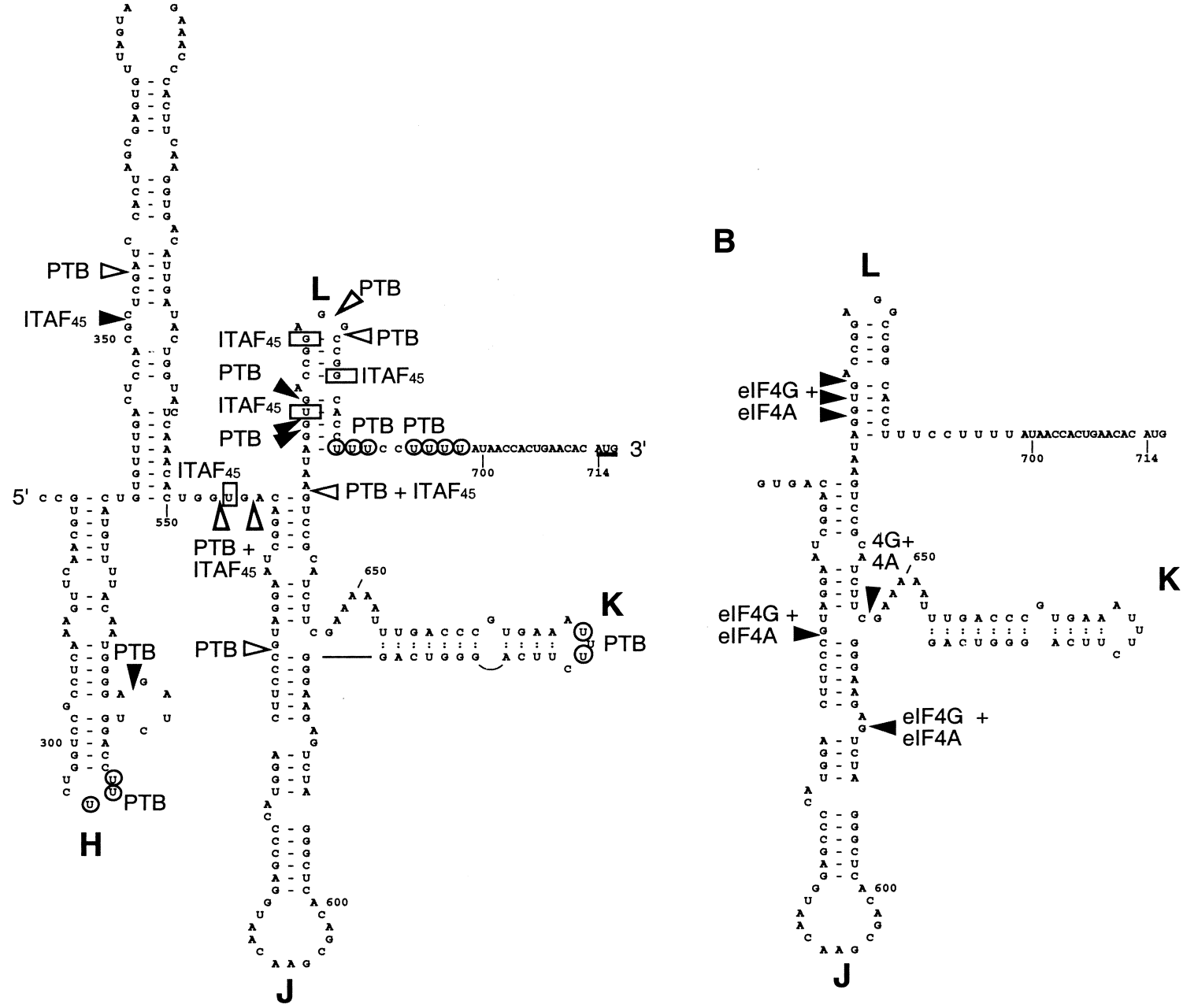

Figure 12. Summary of changes in modification by CMCT and in cleavage by RNAse $\mathrm{T}_{1}$ of the foot-and-mouth disease virus (FMDV) internal ribosomal entry site (IRES) caused by binding of ITAF $_{45}$, PTB, eIF4A, and eIF4G ${ }_{607-1076}$ individually or in combination as indicated. These probes are indicated by symbols, as described in the key at top right. Results are displayed on a secondary structure model (Pilipenko et al. 1989). The initiation codon $\mathrm{AUG}_{714}$ is underlined.

of these picornavirus IRESs, the role of the eIF4G/4A complex may be to prepare the IRES for attachment of a 43S complex in the vicinity of the initiation codon, for example, by interaction with associated factors such as eIF3 and eIF4B or by causing conformational changes in the IRES/factor RNP complex.
The role of IRES trans-acting factors in internal ribosomal entry

The requirement for PTB in FMDV IRES-mediated initiation is consistent with previous reports that it binds specifically to this IRES (Luz and Beck 1990; Kolupaeva 
et al. 1996) and is involved in FMDV translation (Niepman 1995). However, PTB alone is not sufficient to enhance 48S complex formation above background levels on GD68 and GD80 mRNAs, and its activity is dependent on a second factor, $\mathrm{ITAF}_{45} . \mathrm{ITAF}_{45}$ and PTB bind specifically to nonoverlapping sites on the FMDV IRES and individually and together cause localized structural changes in adjacent regions of it (Figs. 10-12). These two ITAFs enhance binding of the eIF4G/4A complex to the IRES and likely promote their assembly into a stable RNP complex (Fig. 10). The binding sites for protein components of this RNP complex include all IRES domains except for the apical region of domain I and extend from the $5^{\prime}$ border of the IRES to within $15 \mathrm{nt}$ of the initiation codon. The latter distance is only slightly greater than the number of residues upstream of the initiation codon of an mRNA that are covered by the $40 \mathrm{~S}$ ribosomal subunit (Legon 1976; Kozak 1977). Ribosomes are recruited to the FMDV IRES at or immediately upstream of the initiation codon at the 3 ' border of the IRES without scanning from an upstream position (Belsham 1992; Lopez de Quinto and Martinez-Salas 1999). The function of ITAFs on the FMDV IRES may therefore be to prepare an RNP complex that contains RNA and protein binding determinants for components of the $43 \mathrm{~S}$ complex oriented in three dimensions in such a way that it can be recruited and loaded onto the mRNA precisely, placing the initiation codon at the ribosomal $\mathrm{P}$ site.

A robust model for IRES-mediated initiation should be able to account for the significant differences between closely related IRESs in their requirement for ITAFs. For example, ribosomal attachment to the initiation codon without scanning is also characteristic of EMCV and TMEV IRES (Kaminski et al. 1990; Pilipenko et al. 1994). There is significant conservation of sequence and structure between EMCV, TMEV, and FMDV IRESs (Pilipenko et al. 1989; Jackson and Kaminski 1995), and as described above, initiation on each of them requires the same set of canonical factors and involves the same interaction between the eIF4G/4A complex and the IRES J-K domain. EMCV, FMDV, and TMEV IRESs all bind PTB with high affinity (Jang and Wimmer 1990; Luz and Beck 1990; Witherell et al. 1993; Kaminski et al. 1995), and the location of PTB binding sites on them appears to be similar, although not identical (Kolupaeva et al. 1996). We have reported here that $\mathrm{ITAF}_{45}$ can be strongly UV cross-linked to both TMEV and FMDV IRESs (Fig. 9). Despite these many similarities, initiation on the EMCV IRES is only weakly dependent on PTB, initiation on the TMEV IRES is strongly dependent on PTB, and initiation on the FMDV IRES is strongly dependent both on PTB and on a second protein, $\mathrm{ITAF}_{45}$, that has no influence on EMCV or TMEV IRESs. Differences in the ITAF requirement for these three IRESs must therefore be related to the small sequence and structural differences between them.

One hypothesis is that ITAFs have a chaperone activity (cf. Herschlag 1995) that functions in IRES-mediated initiation to remodel aberrantly folded IRESs so that they achieve and maintain an active conformation. This hypothesis is supported by the finding that EMCV IRESmediated translation (which does not require PTB) became strongly PTB dependent following insertion of a single extra residue into the A-rich loop between J and $\mathrm{K}$ domains (Kaminski and Jackson 1998). The presence of an additional $A$ residue in this same loop in the IRES of the TMEV GDVII strain relative to the equivalent loop of the TMEV DA strain IRES may account for the apparent difference in their PTB-dependence for activity (Kaminski et al. 1995; this paper). This hypothesis is also consistent with the conclusion that it is the requirement for, rather than the binding of per se, PTB and $\mathrm{ITAF}_{45}$ to EMCV, FMDV, and TMEV IRESs that is altered as a consequence of nucleotide differences between them.

We suggest that the observation that FMDV IRES requires ITAF 45 in addition to PTB, where the TMEV IRES requires only $\mathrm{PTB}$ for activity may reflect sequence differences between these IRESs that lead to differences between them in the mode of binding PTB. For example, cardiovirus (EMCV, TMEV) IRESs contain pyrimidine residues in the bulge between the two helices of domain $\mathrm{K}$ that are specifically bound by PTB (Kolupaeva et al. 1996), whereas analogous residues are not present in the FMDV IRES. We hypothesize that PTB alone cannot fold the FMDV IRES into a functionally competent structure because of such differences in PTB binding sites and that this IRES only achieves an active conformation in the presence of both RNA chaperones, PTB and $\mathrm{ITAF}_{45}$.

It is interesting to note that members of the second major group of picornavirus IRESs are also closely related yet also appear to have different ITAF requirements. Initiation on the poliovirus IRES is strongly dependent on PTB and PCBP2 and does not respond to unr, where in contrast to the poliovirus IRES, initiation on the rhinovirus IRES is strongly dependent on unr and is enhanced by PTB but is less responsive to PCBP2 (Blyn et al. 1997; Hunt and Jackson 1999; Hunt et al. 1999; Walter et al. 1999). Nevertheless, PTB, PCBP2, and unr all bind to both poliovirus and rhinovirus IRESs (Borman et al. 1993; Hellen et al. 1993, 1994; Hunt et al. 1999; Walter et al. 1999; T.V. Pestova, unpubl.).

ITAF $_{45}$ is a proliferation-dependent protein that is distributed throughout the cytoplasm from metaphase through to telophase (Radomski and Jost 1995; Lamartine et al. 1997; Nakagawa et al. 1997). Its expression is up-regulated in response to mitogen stimulation, and it is not detectable in nonproliferating differentiated cells such as murine brain cells (Radomski and Jost 1995). The strict difference in factor requirements for initiation of translation on TMEV and FMDV IRESs is sufficient to limit the activity of the latter, and it is thus tempting to speculate that the requirement for $\mathrm{ITAF}_{45}$ may be a cellspecific determinant that limits replication of the chimeric GD68 and GD80 viruses as well as FMDV. An attractive hypothesis is that $\mathrm{ITAF}_{45}$ may function as a tissue-specific and cell-cycle-dependent factor that specifically binds and controls translation on a particular set of mRNAs during cell proliferation and/or specific phases of the cell cycle. Indeed, IRES-mediated translation of a number of cellular proteins, including ornithine 
decarboxylase, $c$-myc, the p58PITSLRE protein kinase, and platelet-derived growth factor $B$, is specifically activated in a cell-cycle or proliferation-dependent manner (Bernstein et al. 1997; Cornelis et al. 2000; Pyronnet et al. 2000).

\section{Materials and methods}

\section{Plasmids}

Plasmids pET(His $\left.{ }_{6}-\mathrm{eIF} 4 \mathrm{~A}\right)$, pET( $\mathrm{His}_{6}$-eIF4B) (Pestova et al. 1996a), pBS-( $\beta$-globin), and pE15 (Hellen et al. 1993) have been described. Mouse embryo cDNA (Clontech) corresponding to the $\mathrm{ITAF}_{45}$ coding region (Nakagawa et al. 1997) was amplified by PCR using the primers 5'-CGGGATCCGATGTCGGGCGAAGACGAGC-3' and 5'CTCCGCTCGAGTTATCAGTCCCCAGCTCCATTCTC-3', digested with BamH1 and XhoI and inserted into pET28b (Novagen) to yield pET(His $\left.{ }_{6}-\mathrm{ITAF}_{45}\right)$.

Chimeric TMDV/FMDV IRES-luciferase reporter constructs were derived from TMEV GDVII plasmids pUGD (Pilipenko et al. 1994), pGLV and pLG (Pilipenko et al. 1999), and the FMDV $0_{1} \mathrm{~K}$ plasmid pSP449 (Luz and Beck 1990). pLG contains TMEV GDVII nt 1-1124 (corresponding to the entire 5' UTR, the initiation codon, and 18 codons) fused in-frame to the luciferase gene and downstream of a $T_{7}$ promoter. pLGF- 68 and pLGF- 80 were derived from pLG by replacing TMEV nt 628-1047 with FMDV $0_{1} \mathrm{~K}$ nt 280-693 and TMEV nt 628-1124 with FMDV $0_{1} \mathrm{~K}$ nt 280-740, respectively. FMDV nucleotides are numbered starting after the poly $(\mathrm{C})$ tract (Forss et al. 1984). Chimeric fulllength TMEV clones GD68 and GD80 were derived from an infectious full-length wt TMEV GDVII clone GD18 by replacing TMEV nt 628-1047 with FMDV $0_{1} \mathrm{~K}$ nt 280-693 and TMEV nt 628-1124 with FMDV $0_{1} \mathrm{~K}$ nt 280-740, respectively.

\section{Translation of luciferase expressing plasmids}

Plasmids pLG, pLGF-68, and pLGF-80 were linearized with SalI, and mRNA was transcribed, purified, and translated in RRL at $30^{\circ} \mathrm{C}$ for $1 \mathrm{hr}$ (Pilipenko et al. 1994). Template activity was quantified by measurement of $\left[{ }^{35} \mathrm{~S}\right]$ methionine incorporation into the luciferase band separated by SDS-PAGE. For in vivo translation, 1-day-old quadruplicate cultures of BHK-21 cells grown in $50-\mathrm{mm}$ plastic dishes were each transfected with $2 \mu \mathrm{g}$ of mRNA using DEAE-dextran (Pilipenko et al. 1999). Cells were removed after $3 \mathrm{hr}$ incubation at $37^{\circ} \mathrm{C}$, and luciferase activity was determined using the Promega Luciferase Assay System according to the manufacturer's protocol. The signals were normalized to $10^{6}$ cells by determining protein concentration in the lysates using the Lowry method. The signal variation in quadruplicate cultures did not exceed $15 \%$ of the average value for a given template. The saturating amount of RNA in this assay corresponded to $1 \mu \mathrm{g} / \mathrm{dish}$.

\section{Preparation and characterization of chimeric viruses}

Viruses were recovered from transcript RNA-transfected BHK21 cells, accumulated, and characterized (Pilipenko et al. 1994, 1995). A region of the viral RNA (between nt 579 and 1214 of the $w t$ TMEV GDVII sequence) was amplified by RT-PCR and sequenced as described (Pilipenko et al. 1995). No additional sequence changes were detected.

\section{Neurovirulence assay and detection of replicating virus} in mouse CNS

BALB/C mice (10-12 g) were inoculated intracerebrally with tenfold virus dilutions and monitored for clinical signs for 6 week p.i. Thirty mice were inoculated with $10^{8} \mathrm{TCD}_{50}(50 \%$ tissue culture infective dose) of GD68 virus, and 10 mice were each infected with $10^{7} \mathrm{TCD}_{50}-10^{3} \mathrm{TCD}_{50}$ doses. For GD80 virus, 25 mice were inoculated with $10^{7.5} \mathrm{TCD}_{50}$, and 12 mice each with $10^{6.5} \mathrm{TCD}_{50}$ and $10^{5.5} \mathrm{TCD}_{50}$ doses. The paralytogenic activity was expressed as the viral dose causing paralysis in $50 \%$ of animals $\left(\mathrm{PD}_{50}\right)$. The presence of the viral genome in the CNS was detected by RT-PCR amplification of the appropriate region of the viral RNA (nt 579-1214), as described above. Four mice for GD80 and three mice for GD68 were sacrificed at 1-, 7- and 14-day time-points p.i. Forty cycles of PCR amplification were performed with RNA samples extracted from CNS at days 7 and 14 p.i.

\section{Purification of factors and 40 S ribosomal subunits}

Ribosomal subunits, eIF2, eIF3, and eIF4F were purified from RRL as described (Pestova et al. 1996a, 1998b). ITAF 45 was purified from the ribosomal salt wash (RSW) 70\%-95\% ammonium sulfate (AS) precipitation fraction from RRL. This fraction was applied in buffer A (20 mM Tris at pH 7.5, $1 \mathrm{~mm} \mathrm{DTT,} 0.1$ $\mathrm{mM}$ EDTA, $10 \%$ glycerol) containing $100 \mathrm{~mm} \mathrm{KCl}$ to a DEAE cellulose column. The flow-through fraction was applied to a phosphocellulose column and fractionated by step-elution using buffer A with $100 \mathrm{~mm}$ and then $250 \mathrm{~mm}, 400 \mathrm{~mm}, 600 \mathrm{~mm}$ and finally $800 \mathrm{~mm} \mathrm{KCl}$. The active $250-400-\mathrm{mm} \mathrm{KCl}$ elution fraction was dialyzed against buffer A with $50 \mathrm{~mm} \mathrm{KCl}$ and applied in this buffer to an FPLC MonoQ HR 5/5 column. Fractions were collected across a 50-500 $\mathrm{mm} \mathrm{KCl}$ gradient. Peaks of active, apparently homogenous $\mathrm{ITAF}_{45}$ eluted with 185 and 210 mM KCl. Recombinant PTB-1 and eIFs eIF1, eIF1A, eIF4A, and eIF4B were purified as described (Pestova et al. 1996a, 1998a). Recombinant $\mathrm{ITAF}_{45}$ was expressed in Escherichia coli BL21(DE3) and purified by $\mathrm{Ni}^{2+}$-NTA (Qiagen) and MonoQ HR $5 / 5$ column chromatography.

\section{Sequencing of ITAF 45}

Purified $\mathrm{ITAF}_{45}$ was resolved by gel electrophoresis. Sequencing of two well-resolved $\mathrm{ITAF}_{45}$ tryptic peptides was done as described (Pestova et al. 1998a,b).

\section{Assembly and analysis of ribosomal and ribonucleoprotein complexes}

For toeprinting analysis, ribosomal complexes were assembled essentially as described (Pestova et al. 1998a). For $5 \mathrm{~min}, 0.5 \mu \mathrm{g}$ of GD18, GD68, or GD80 mRNA were incubated at $30^{\circ} \mathrm{C}$ in a 40- $\mu$ l reaction volume that contained buffer B $(2 \mathrm{~mm}$ DTT, 100 mM KAc, 20 mм Tris at $\mathrm{pH} 7.6,2.5 \mathrm{~mm} \mathrm{MgAc}, 1 \mathrm{~mm}$ ATP, 0.1 mM GMPPNP, $0.25 \mathrm{~mm}$ spermidine), eIF2 (3 $\mu \mathrm{g})$, eIF3 (6 $\mu \mathrm{g})$, eIF4A ( $2 \mu \mathrm{g})$, eIF4B $(0.3 \mu \mathrm{g})$, eIF4F $(1.5 \mu \mathrm{g}), 6$ pmole of $40 \mathrm{~S}$ subunits, and 6 pmole of Met-tRNA ${ }_{i}^{\text {Met }}$ and with or without PTB $(0.5 \mu \mathrm{g})$, ITAF $_{45}(1 \mu \mathrm{g})$, eIF1 $(0.3 \mu \mathrm{g})$, eIF1A $(0.3 \mu \mathrm{g})$, or different RSW fractions (4-8 $\mu \mathrm{g}$ protein), as indicated. Incubation was continued for $3 \mathrm{~min}$ at $30^{\circ} \mathrm{C}$ following addition of 4 pmole of primer 5'-CCAGAAGACGTCATCGTCCA-3' (complementary to TMEV nt 1195-1214). Ribosomal and RNP complexes were analyzed by primer extension (Pestova et al. 1996a) using avian myeloblastosis virus (AMV) reverse transcriptase (Promega) in the presence of $\left[\alpha-{ }^{32} \mathrm{P}\right] \mathrm{dATP}(\sim 6000 \mathrm{Ci} / \mathrm{mmole}$; ICN Radiochemicals). cDNA products were compared with appropriate dideoxynucleotide sequence ladders.

For toeprinting analysis of $48 \mathrm{~S}$ complexes assembled in $\mathrm{RRL}$, $0.5 \mu \mathrm{g}$ of RNA was incubated in $15 \mu \mathrm{l}$ of RRL in the presence of $1 \mathrm{mM}$ GMPPNP for $5 \mathrm{~min}$ at $30^{\circ} \mathrm{C}$. The reaction mixture was 
diluted with buffer B to $40 \mu$ final volume before the addition of 4 pmole of primer 5'-CCAGAAGACGTCATCGTCCA-3' complementary to TMEV nt 1195-1214. Toeprint analysis was done as described above.

Ribonucleoprotein (RNP) complexes were formed by incubating eIFs and FMDV IRES mRNA for $5 \mathrm{~min}$ at $30^{\circ} \mathrm{C}$ in buffer (100 mm KAc, 2 mm MgAc, 2 mm Tris- $\mathrm{HCl}$ at $\mathrm{pH} 7.5,1 \mathrm{~mm}$ DTT). Reactions contained $1 \mu \mathrm{g}$ of RNA (4 pmole), $1 \mu \mathrm{g}$ of eIF4G $\mathrm{G}_{607-1076}(10$ pmole), $1 \mu \mathrm{g}$ of eIF4A (22 pmole), $1.5 \mu \mathrm{g}$ (21 pmole) of eIF4B, and $0.75 \mu \mathrm{g}$ (12 pmole) of PTB and ATP (1mM), as indicated in the text, in a 20- $\mu$ l volume. Toeprint analysis of FMDV mRNA/factor complexes was done essentially as described (Pestova et al. 1996a,b), using the primer 5'CCAGAAGACGTCATCGTCCA-3' (complementary to TMEV nt 1214-1195).

Ribosomal complexes were assembled for analysis by sucrosedensity gradient centrifugation essentially as described above for toeprinting analysis, except that the reaction volume was increased to $100 \mu \mathrm{l}$ and mRNAs were labeled during transcription with $\left[{ }^{32} \mathrm{P}\right] \mathrm{UTP}(\sim 3000 \mathrm{Ci} / \mathrm{mmole}$; ICN Radiochemicals) to a specific activity of $200,000 \mathrm{cpm} / \mathrm{\mu g}$. Reaction mixtures containing translation components as indicated in the text were incubated for $5 \mathrm{~min}$ at $30^{\circ} \mathrm{C}$. $48 \mathrm{~S}$ and RNP complexes were resolved by centrifugation through 10\%-30\% sucrose-density gradients as described (Pestova et al. 1996a).

\section{$U V$ cross-linking of $I_{T A F_{45}}$ to $R N A$}

The UV cross-linking reaction was done using a UV-Stratalinker (Stratagene) essentially as described (Pestova et al. 1996b). Purified wt TMEV RNA, chimeric GD80 RNA, or $\beta$-globin RNA (100 ng) that had been labeled with $\left[{ }^{32} \mathrm{P}\right]$ UTP during transcription with $T_{7}$ polymerase were incubated for $10 \mathrm{~min}$ at $30^{\circ} \mathrm{C}$ in a $20 \mu \mathrm{l}$ reaction volume containing buffer B and $\mathrm{ITAF}_{45}$ (3 $\mu \mathrm{g}$ ) either with or without competitor RNAs, as indicated in the text. Samples were digested with cobra venom nuclease and RNAse A. Proteins were separated by $12 \%$ SDS-PAGE.

\section{Chemical and enzymatic footprinting}

RNP complexes were probed with RNase $\mathrm{T}_{1}$ and CMCT as described (Kolupaeva et al. 1996, 1998). Cleaved or modified sites were identified by primer extension, using AMV RT and the primers 5'-CCAGAAGACGTCATCGTCCA-3' (complementary to TMEV nt 1214-1195), 5'-CAGTCAGTTGTATTCATG3 ' (complementary to FMDV nt 730-713), or 5'-CCAGTATCAATGTCACC-3' (complementary to FMDV nt 539-523), as appropriate.

\section{Acknowledgments}

We thank E. Beck for the FMDV plasmid and L. Siconolfi-Baez for sequencing $\mathrm{ITAF}_{45}$. This study was supported by grant MCB9726958 from the National Science Foundation to C.U.T.H., by a grant from the Russian Foundation of Basic Research to V.I.A., and by grants from the U.S. Civilian Research and Development Foundation (RB1-271) and the International Association for the promotion of cooperation with scientists from the former Soviet Union (INTAS-97-0501) to E.V.P.

The publication costs of this article were defrayed in part by payment of page charges. This article must therefore be hereby marked "advertisement" in accordance with 18 USC section 1734 solely to indicate this fact.

\section{References}

Arfin, S.M., Kendall, R.L., Hall, L., Weaver, L.H., Stewart, A.E., Matthews, B.W., and Bradshaw, R.A. 1995. Eukaryotic me- thionyl aminopeptidases: two classes of cobalt-dependent enzymes. Proc. Nat1. Acad. Sci. 92: 7714-7718.

Aubert, C. and Brahic, M. 1995. Early infection of the central nervous system by the GDVII and DA strains of Theiler's virus. J. Virol. 69: 3197-3200.

Bachrach, H.L. 1968. Foot-and-mouth disease. Annu. Rev. Microbiol. 22: 201-244.

Belsham, G.J. 1992. Dual initiation sites of protein synthesis on foot-and-mouth disease virus RNA are selected following internal entry and scanning of ribosomes in vivo. EMBO $\mathrm{J}$. 11: 1105-1110.

Bernstein, J., Sella, O., Le, S.Y., and Elroy-Stein, O. 1997. PDGF2/c-sis mRNA leader contains a differentiation-linked internal ribosomal entry site (D-IRES). I. Biol. Chem. 272: 9356-9362.

Blyn, L.B., Swiderek, K.M., Richards, O., Stahl, D.C., Semler, B.L., and Ehrenfeld, E. 1996. Poly(rC) binding protein 2 binds to stem-loop IV of the poliovirus RNA $5^{\prime}$ noncoding region: Identification by automated liquid chromatography-tandem mass spectrometry. Proc. Natl. Acad. Sci. 93: 11115-11120.

Blyn, L.B., Towner, J.S., Semler, B.L., and Ehrenfeld, E. 1997. Requirement of poly $(\mathrm{rC})$ binding protein 2 for translation of poliovirus RNA. J. Virol. 71: 6243-6246.

Borman, A., Howell, M.T., Patton, J., and Jackson, R.J. 1993. The involvement of a spliceosome component in internal initiation of human rhinovirus RNA translation. J. Gen. Virol. 74: 1775-1788.

Brown, B.A. and Ehrenfeld, E. 1979. Translation of poliovirus RNA in vitro: Changes in cleavage pattern and initiation sites by ribosomal salt wash. Virology 97: 396-405.

Cornelis, S., Bruynooghe, Y., Denecker, G., van Huffel, S., Tinton, S., and Beyaert, R. 2000. Identification and characterization of a novel cell cycle-regulated internal ribosome entry site. Mol. Cell 5: 597-605.

Dorner, A.J., Semler, B.L., Jackson, R.J., Hanecak, R., Duprey, E., and Wimmer, E. 1984. In vitro translation of poliovirus RNA: Utilization of internal initiation sites in reticulocyte lysate. J. Virol. 50: 507-514.

Ehresmann, C., Baudin, F., Mougel, M., Romby, P., Ebel, J.P., and Ehresmann, B. 1987. Probing the structure of RNA in solution. Nucleic Acids Res. 15: 9109-9128.

Forss, S.K., Strebel, K., Beck, E., and Schaller, H. 1984. Nucleotide sequence and genome organization of foot-and-mouth disease virus. Nucleic Acids Res. 12: 6587-6601.

Gamarnik, A.V. and Andino, R. 2000. Interactions of viral protein $3 \mathrm{CD}$ and Poly $(\mathrm{rC})$ binding protein with the $5^{\prime}$ untranslated region of the poliovirus genome. I. Virol. 74: 2219-2226.

Gellner, K. and Brenner, S. 1999. Analysis of $148 \mathrm{~kb}$ of genomic DNA around the wnt1 locus of Fugu rubripes. Genome Res. 9: 251-258.

Gray, N.K. and Wickens, M. 1998. Control of translation initiation in animals. Ann. Rev. Cell. Dev. Biol. 14: 399-458.

Gromeier, M., Alexander, L., and Wimmer, E. 1996. Internal ribosomal entry site substitution eliminates neurovirulence in intergeneric poliovirus recombinants. Proc. Natl. Acad. Sci. 93: 2370-2375.

Hellen, C.U.T, Pestova, T.V., Litterst, M., and Wimmer, E. 1994. The cellular polypeptide p57 (pyrimidine tract-binding protein) binds to multiple sites in the poliovirus 5 ' nontranslated region. J. Virol. 68: 941-950.

Hellen, C.U.T., Witherell, G.W., Schmidt, M., Shin, S.H., Pestova, T.V., Gil, A., and Wimmer, E. 1993. A cytoplasmic $57 \mathrm{kDa}$ protein that is required for translation of picornavirus RNA by internal ribosomal entry is identical to the nuclear pyrimidine tract-binding protein. Proc. Natl. Acad. Sci. 
90: 7642-7646.

Hentze, M.W. and Kühn, L.C. 1996. Molecular control of vertebrate iron metabolism: mRNA-based regulatory circuits operated by iron, nitric oxide, and oxidative stress. Proc. Natl. Acad. Sci. 93: 8175-8182

Herschlag, D. 1995. RNA chaperones and the RNA folding problem. J. Biol. Chem. 270: 20871-20874.

Hunt, S.L., Hsuan, J.J., Totty, N., and Jackson, R.J. 1999. unr, a cellular cytoplasmic RNA-binding protein with five coldshock domains, is required for internal initiation of translation of human rhinovirus RNA. Genes \& Dev. 13: 437-448.

Hunt, S.L. and Jackson, R.J. 1999. Polypyrimidine tract-binding protein $(\mathrm{PTB})$ is necessary, but not sufficient, for efficient internal initiation of translation of human rhinovirus-2. RNA 5: 344-359.

Jackson, R.J. and Kaminski, A. 1995. Internal initiation of translation in eukaryotes: The picornavirus paradigm and beyond. RNA 1: 985-1000.

Jang, S.K. and Wimmer, E. 1990. Cap-independent translation of encephalomyocarditis virus RNA: Structural elements of the internal ribosomal entry site and involvement of a cellular 57-kD RNA-binding protein. Genes \& Dev. 4: 15601572.

Kaminski, A., Howell, M.T., and Jackson, R.J. 1990. Initiation of encephalomyocarditis virus RNA translation: The authentic initiation site is not selected by a scanning mechanism. EMBO J. 9: 3753-3759.

Kaminski, A., Hunt, S.L., Patton, J.G., and Jackson, R.J. 1995. Direct evidence that polypyrimidine tract binding protein (PTB) is essential for internal initiation of translation of encephalomyocarditis virus RNA. RNA 1: 924-938.

Kaminski, A. and Jackson, R.J. 1998. The polypyrimidine tract binding protein (PTB) requirement for internal initiation of translation of cardiovirus RNAs is conditional rather than absolute. RNA 4: 626-638.

Kolupaeva, V.G., Hellen, C.U.T., and Shatsky, I.N. 1996. Structural analysis of the interaction of the pyrimidine tract-binding protein with the internal ribosomal entry site of encephalo-myocarditis virus and foot-and-mouth disease virus RNAs. RNA 2: 1179-1188.

Kolupaeva, V.G., Pestova, T.V., Hellen, C.U.T., and Shatsky, I.N. 1998. Translation initiation factor eIF4G recognizes a specific structural element within the internal ribosomal entry site of encephalomyocarditis virus RNA. I. Biol. Chem. 273: 18599-18604.

Kozak, M. 1977. Nucleotide sequences of $5^{\prime}$-terminal ribosomeprotected initiation regions from two reovirus messages. $\mathrm{Na}$ ture 269: 390-394.

Kühn, R., Luz, N., and Beck, E. 1990. Functional analysis of the internal translation initiation site of foot-and-mouth disease virus. J. Virol. 64: 4625-4631.

Lamartine, J., Seri, M., Cinti, R., Heitzmann, F., Creaven, M., Radomski, N., Jost, E., Lenoir, G.M., Romeo, G., and Sylla, B.S. 1997. Molecular cloning and mapping of a human cDNA (PA2G4) that encodes a protein highly homologous to the mouse cell cycle protein p38-2G4. Cytogen. Cell Genet. 78: 31-35.

Law, K.M. and Brown, T.D.K. 1990. The complete nucleotide sequence of the GDVII strain of Theiler's murine encephalomyelitis virus (TMEV). Nucleic Acids Res. 18: 6707-6708.

Legon, S. 1976. Characterization of the ribosome-protected regions of ${ }^{125}$ I-labelled rabbit globin messenger RNA. J. Mol. Biol. 106: 37-53.

Lomakin, I.B., Hellen, C.U.T., and Pestova, T.V. 2000. Physical association of eIF4G with eIF4A strongly enhances binding of eIF4G to the internal ribosomal entry site of encephalo- myocarditis virus and is required for internal initiation of translation. Mol. Cell. Biol. 20: 6019-6029.

Lopez de Quinto, S. and Martinez-Salas, E. 1999. Involvement of the aphthovirus RNA region located between the two functional AUGs in start codon selection. Virology 255: 324-336.

Luz N. and Beck, E. 1990. A cellular 57kDa protein binds to two regions of the internal translation initiation site of foot-andmouth disease virus. FEBS Lett. 269: 311-314.

Meerovitch, K., Svitkin, Y.V., Lee, H.S., Lejbkowicz, F., Kenan, D.J., Chan, E. K., Agol, V.I., Keene, J.D., and Sonenberg, N. 1993. La autoantigen enhances and corrects aberrant translation of poliovirus RNA in reticulocyte lysate. J. Virol. 67: 3798-3807.

Morino, S., Imataka, H., Svitkin, Y.V., Pestova, T.V., and Sonenberg, N. 2000. Eukaryotic translation initiation factor 4E (eIF4E) binding site and the middle one-third of eIF4GI constitute the core domain for cap-dependent translation, and the C-terminal one-third functions as a modulatory region. Mol. Cell. Biol. 20: 468-477.

Muckenthaler M., Gray, N.K., and Hentze, M.W. 1998. IRP-1 binding to ferritin mRNA prevents the recruitment of the small ribosomal subunit by the cap-binding complex eIF4F. Mol. Cell 2: 383-388.

Nakagawa, Y., Watanabe, S., Akiyama, K., Sarker, A.H., Tsutsui, K., Inoue, H., and Seki, S. 1997. cDNA cloning, sequence analysis and expression of a mouse 44-kDa nuclear protein copurified with DNA repair factors for acid-depurinated DNA. Acta Med. Okayama 51: 195-206.

Niepmann, M. 1995. Porcine polypyrimidine tract-binding protein stimulates translation initiation at the internal ribosome entry site of foot-and-mouth disease virus. FEBS Lett. 388: 39-42.

Pestova, T.V., Hellen, C.U.T., and Shatsky, I.N. 1996a. Canonical eukaryotic initiation factors determine initiation of translation by internal ribosomal entry. Mol. Cell. Biol. 16: 6859-6869.

Pestova, T.V., Shatsky, I.N., and Hellen, C.U.T. 1996b. Functional dissection of eukaryotic initiation factor 4F: The 4A subunit and the central domain of the 4G subunit are sufficient to mediate internal entry of $43 \mathrm{~S}$ preinitiation complexes. Mol. Cell. Biol. 16: 6870-6878.

Pestova, T.V., Borukhov, S.I., and Hellen, C.U.T. 1998a. Eukaryotic ribosomes require initiation factors 1 and $1 \mathrm{~A}$ to locate initiation codons. Nature 394: 854-859.

Pestova, T.V., Shatsky, I.N., Fletcher, S.P., Jackson, R.J., and Hellen, C.U.T. 1998b. A prokaryotic-like mode of binding of cytoplasmic eukaryotic ribosomes to the initiation codon during internal initiation of translation of Hepatitis C and classical swine fever virus RNAs. Genes \& Dev. 12: 67-83.

Pilipenko, E.V., Blinov, V.M., Chernov, B.K., Dmitrieva, T.M., and Agol, V.I. 1989. Conservation of the secondary structure elements of the $5^{\prime}$-untranslated region of cardio- and aphthovirus RNAs. Nucleic Acids Res. 17: 5701-5711.

Pilipenko, E.V., Gmyl, A.P., Maslova, S.V., Belov, G.A., Sinyakov, A.N., Huang, M., Brown, T.D.K., and Agol, V.I. 1994. Starting window, a distinct element in the cap-independent internal initiation of translation on picornaviral RNA. $J$. Mol. Biol. 241: 398-414.

Pilipenko, E.V., Gmyl, A.P., Maslova, S.V., Khitrina, E.V., and Agol, V.I. 1995. Attenuation of Theiler's murine encephalomyelitis virus by modifications of the oligopyrimidine/AUG tandem, a host-dependent translational cis element. J. Virol. 69: $864-870$.

Pilipenko, E.V., Viktorova, E.G., Khitrina, E.V., Maslova, S.V., Jarousse, N., Brahic, M., and Agol, V.I. 1999. Distinct attenuation phenotypes caused by mutations in the translational 
starting window of Theiler's murine encephalomyelitis virus. J. Virol. 73: 3190-3196.

Pritchard, A.E., Calenoff, M.A., Simpson, S., Jensen, K., and Lipton, H.L. 1992. A single base deletion in the $5^{\prime}$ noncoding region of Theiler's virus attenuates neurovirulence. J. Virol. 66: 1951-1958.

Pyronnet, S., Pradayrol, L., and Sonenberg, N. 2000. A cell cycle-dependent internal ribosome entry site. Mol. Cell 5: 607-616.

Radomski, N. and Jost, E. 1995. Molecular cloning of a murine cDNA encoding a novel protein, p38-2G4, which varies with the cell cycle. Exp. Cell Res. 220: 434-445.

Ray, M.K., Chakraborty, A., Datta, B., Chattopadhyay, A., Satta, D., Bose, A., Kinzy, T.G., Wu, S., Hileman, R.E., Merrick, W.C., and Gupta, N.K. 1993. Characteristics of the eukaryotic initiation factor 2 associated $67-\mathrm{kDa}$ polypeptide. Biochemistry 32: 5151-5159.

Standart, N. and Jackson, R.J. 1994. Regulation of translation by specific protein/mRNA interactions. Biochimie 76: 867879.

Svitkin, Y.V., Maslova, S.V., and Agol, V.I. 1985. The genomes of attenuated and virulent poliovirus strains differ in their in vivo translation efficiences. Virology 147: 243-252.

Svitkin, Y.V., Meerovitch, K., Lee, H.S., Dholakia, J.N., Kenan, D.J., Agol, V. I., and Sonenberg, N. 1994. Internal translation initiation on poliovirus RNA: further characterization of La function in poliovirus translation in vitro. J. Virol. 68: 1544 1550.

Svitkin, Y.V., Pestova, T.V., Maslova, S.V., and Agol, V.I. 1988. Point mutations modify the response of poliovirus RNA to a translation initiation factor: a comparison of neurovirulent and attenuated strains. Virology 166: 394-404.

Tahirov, T.H., Oki, H., Tsukihara, T., Ogasahara, K., Yutani, K. Ogata, K., Izu, Y., Tsunasawa, S., and Kato, I. 1998. Crystal structure of methionine aminopeptidase from hyperthermophile, Pyrococcus furiosus. J. Mol. Biol. 284: 101-124.

Theiler, M. 1937. Spontaneous encephalomyelitis of mice, a new virus disease. J. Exp. Med. 65: 705-719.

Walter, B.L., Nguyen, J.H.C., Ehrenfeld, E., and Semler, B.L. 1999. Differential utilization of poly $(\mathrm{rC})$ binding protein 2 in translation directed by picornavirus IRES elements. RNA 5: 1570-1585.

Witherell, G.W., Gil, A., and Wimmer, E. 1993. Interaction of polypyrimidine tract binding protein with the encephalomyocarditis virus mRNA internal ribosomal entry site. Biochemistry 32: 8268-8275

Yamada, H., Mori, H., Momoi, H., Nakagawa, Y., Ueguchi, C., and Mizuno, T. 1994. A fission yeast gene encoding a protein that preferentially associates with curved DNA. Yeast 10: $883-894$. 


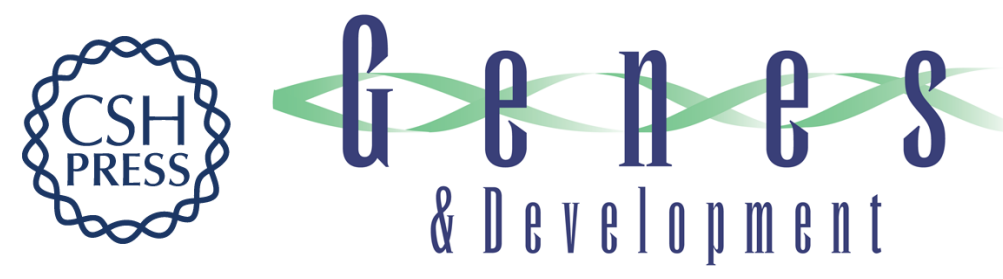

\section{A cell cycle-dependent protein serves as a template-specific translation initiation factor}

Evgeny V. Pilipenko, Tatyana V. Pestova, Victoria G. Kolupaeva, et al.

Genes Dev. 2000, 14:

Access the most recent version at doi:10.1101/gad.14.16.2028

References This article cites 62 articles, 33 of which can be accessed free at: http://genesdev.cshlp.org/content/14/16/2028.full.html\#ref-list-1

License

Email Alerting

Receive free email alerts when new articles cite this article - sign up in the box at the top Service right corner of the article or click here.

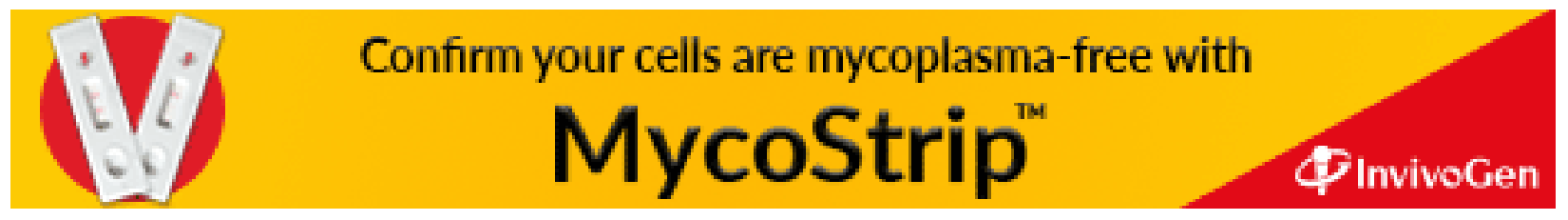

